\title{
Advanced Simulations of Reusable Hypersonic Rocket-Powered Stages
}

\author{
Martin Sippel, Leonid Bussler, Alexander Kopp, Sven Krummen, Cecilia Valluchi, Jascha Wilken \\ Space Launcher Systems Analysis (SART), DLR, Bremen, Germany \\ Ysolde Prévereaud, Jean-Luc Vérant, Emmanuel Laroche, Fréderic Sourgen \\ ONERA- The French Aerospace Lab, Toulouse, France \\ Davide Bonetti \\ DEIMOS Space S.L.U., Madrid, Spain
}

\begin{abstract}
After successful completion of the MRR, technical progress of the SpaceLiner ultra-high-speed rocketpropelled passenger transport is achieved in Phase A conceptual design work. Following geometry refinement the structural design is maturing based on extensive trade-offs. Aerodynamics are investigated by numerical CFD-simulations of the two winged stages and will be supported by windtunnel tests.
\end{abstract}

Aerodynamic control surfaces of the passenger cabin and rescue capsule and its subsystems are defined. Alternative options for the capsule with innovative morphing shapes are critically investigated taking into account system aspects, structural design, and advanced CFD-simulations.

Potential intercontinental flight routes, considering range-safety and sonic boom constraints as well as good reachability from major business centers, are evaluated and flight guidance schemes are established. Extensions to this trajectory model are implemented to investigate the attitude dynamics and related controllability issues of the asymmetric launcher configuration.

The space transportation role of the SpaceLiner concept as a TSTO-launcher is now addressed in technical detail.

$\begin{array}{ll}\text { CAD } & \text { Computer aided design } \\ \text { CEDRE } & \text { Calcul d'Écoulements Diphasiques Réactifs pour l'Énergétique (CFD tool of ONERA) } \\ \text { CFD } & \text { Computational Fluid Dynamics } \\ \text { CMC } & \text { Ceramic Matrix Composites } \\ \text { GLOW } & \text { Gross Lift-Off Mass } \\ \text { IXV } & \text { Intermediate eXperimental Vehicle (of ESA) } \\ \text { LH2 } & \text { Liquid Hydrogen } \\ \text { LOX } & \text { Liquid Oxygen } \\ \text { MRR } & \text { Mission Requirements Review } \\ \text { RCS } & \text { Reaction Control System } \\ \text { RLV } & \text { Reusable Launch Vehicle } \\ \text { SLME } & \text { SpaceLiner Main Engine } \\ \text { TAEM } & \text { Terminal Area Energy Management } \\ \text { TPS } & \text { Thermal Protection System } \\ \text { TSTO } & \text { Two-Stage-To-Orbit } \\ \text { TVC } & \text { Thrust Vector Control }\end{array}$

\section{Introduction}

The key premise behind the original concept inception is that the SpaceLiner ultimately has the potential to enable sustainable low-cost space transportation to orbit while at the same time revolutionizing ultra-long distance travel between different points on Earth. The number of launches per year should be strongly raised and hence manufacturing and operating cost of launcher hardware should dramatically shrink. 
Ultra-long distance travel from one major business center of the world to another major agglomeration on earth is a huge and mature market. Since the termination of Concorde operation, intercontinental travel is restricted to lowspeed, subsonic, elongated multi-hour flight. An interesting alternative to air-breathing hypersonic passenger airliners in the field of future high-speed intercontinental passenger transport vehicles is a rocket-propelled, suborbital craft. Such a new kind of 'space tourism' based on a two stage RLV has been proposed by DLR under the name SpaceLiner [1]. Ultra-long-haul distances like Europe - Australia could be flown in 90 minutes. Other interesting intercontinental destinations between e.g. East-Asia and Europe or the Trans-Pacific-route to North-West America could be reduced to flight times of slightly more than one hour [20, 23, 34].

Ultra-fast transportation far in excess of supersonic and even potential hypersonic airplanes is definitely a fundamental new application for launch vehicles. By no more than partially tapping the huge intercontinental travel and tourism market, production rates of RLVs and their rocket engines could increase hundredfold which is out of reach for all other known earth-orbit space transportation. The fast intercontinental travel space tourism, not only attracting the leisure market, would, as a byproduct, also enable to considerably reduce the cost of space transportation to orbit as demonstrated by vehicle design and cost estimations in [37].

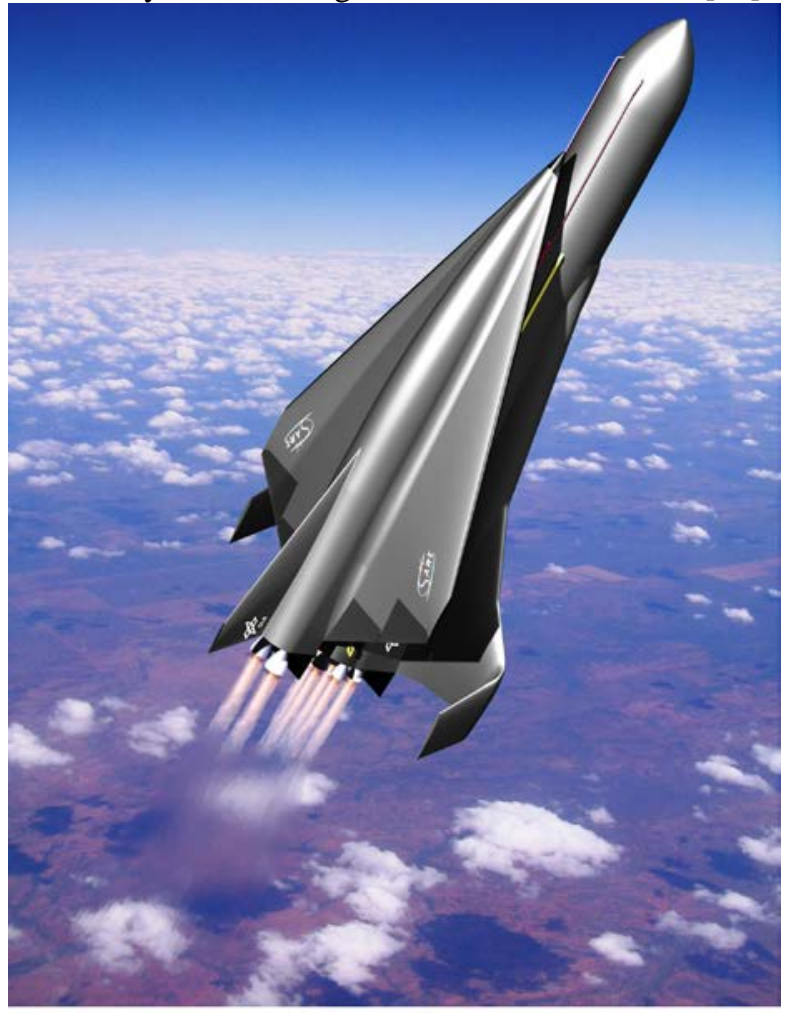

Figure 1: The SpaceLiner vision of a rocket-propelled intercontinental passenger transport is one of the most challenging projects in hypersonic research

The functionality of rocket propulsion is a proven technology since decades and their performance characteristics are well known. Furthermore, a rocket powered RLV-concept like the SpaceLiner is highly attractive because the flight durations are two to three times lower than those of even the most advanced airbreathing systems. Although additional times for travel are to be accounted, the actual time needed for travelling with the SpaceLiner might still be reduced by $75 \%$ to $80 \%$ compared to conventional subsonic airliner operation [7, 9]. In contrast to the first generation of SST, thus a substantial advantage in travel times and hence improved business case can be expected.

An early assessment of the SpaceLiner's potential business case is described in the references 1, 2, and 5. A more detailed market analyses has been performed and results are published in [22, 23]. An operational scenario of the integrated door-to-door travel concept and the comparison with conventional intercontinental travel options are described in [35]. 


\section{A. Status of Previous Technical Development}

First proposed in 2005 [1], the SpaceLiner is under constant development and descriptions of some major updates have been published since then [2, 14, 23, 35, 37]. The European Union's $7^{\text {th }}$ Research Framework Programme has supported several important aspects of multidisciplinary and multinational cooperation in the projects FAST20XX [8, 20], CHATT [17, 18], HIKARI [19], and HYPMOCES [38, 42].

Different configurations in terms of propellant combinations, staging, aerodynamic shapes, and structural architectures have been analyzed. A subsequent configuration numbering has been established for all those types investigated in sufficient level of detail. The genealogy of the different SpaceLiner versions is shown in reference 35. These configuration studies supported the definition of the current reference configuration SpaceLiner 7. An overview on the interim research configurations $3,4,5$, and 6 can be found in [10].

Another important milestone has been reached in 2016 with the successful completion of the Mission Requirements Review (MRR) which allows the concept to mature from research to structured development [37]. The Mission Requirements Document (MRD) [9] constitutes the top-level mission requirements of the SpaceLiner System. The MRD is the baseline and starting point for all technical and programmatic follow-on activities of the SpaceLiner Program.

\section{B. Mission Definition}

The ambitious west-bound Australia - Europe mission has been used as the reference case since the beginning of the SpaceLiner investigations. This flight distance should be served for 50 passengers on a daily basis in each direction. Several other, shorter intercontinental missions exist, which potentially generate a larger market demand. For this reason a SpaceLiner configuration derivative has been studied, which could transport up to 100 passengers [34]. In order to keep the number of different stage configurations at the lowest possible level, the potentially interesting flight destinations have been divided into three classes [35]. These three mission classes could be flexibly served by a suitable combination of four different vehicles (however with a lot of commonality in subcomponents like engines): 50 and 100 Passenger orbiter stage and large and shortened booster.

\section{Configuration Definition}

The SpaceLiner has developed into a relatively complex System (now referred to as SLS) which includes the SpaceLiner Vehicle (SLV) as well as the SpaceLiner Ground Segment (SLGS). Two different SpaceLiner versions exist as presented in Figure 2. The "PAX"-version is the point-to-point ultra-fast passenger transport vehicle consisting of the Booster (SLB) and Passenger stage (SLP) including the cabin (SLC) powered by the main engine (SLME). The orbital version represents the SLB and the Orbiter (SLO) designed to operate as a space transportation system used for payloads delivery to and from orbit with maximum technical similarities to the passenger version. This configuration is described in section VII-B and [37].
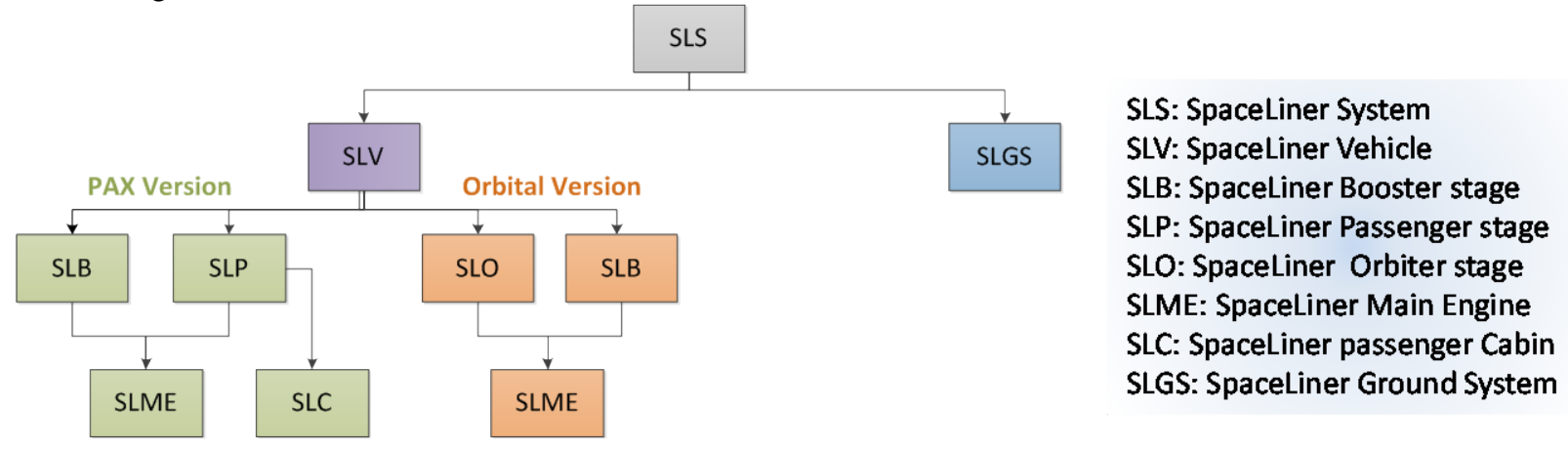

Figure 2: A visual representation of the association and relation between the various SpaceLiner System elements [9]

\section{SpaceLiner 7 Architecture and Geometry}

Since the last hypersonic systems overview paper on the SpaceLiner [35] significant technical progress related to the overall launch configuration as well as to both stages, the reusable booster and the orbiter or passenger stage, has been achieved. The current arrangement of the two vehicles at lift-off is presented in Figure 3. Stage attachments are following a classical tripod design. The axial thrust of the booster is introduced through the forward attachment from 
booster intertank into the nose gear connection structure of the orbiter. The aft attachment takes all side and maneuvering loads. The option of a belly to belly connection is not preferred for two reasons: A strong unintended aerodynamic interaction of the two wings and propellant crossfeed lines on the booster which would be directly affected by hypersonic flow during reentry of this stage. All LOX-feedlines and the LH2-crossfeed connection are attached on the booster's top outer side, thus, subjected to flow in the relatively cold wake region. The feedlines of the upper stage are completely internal and ducted underneath the TPS.

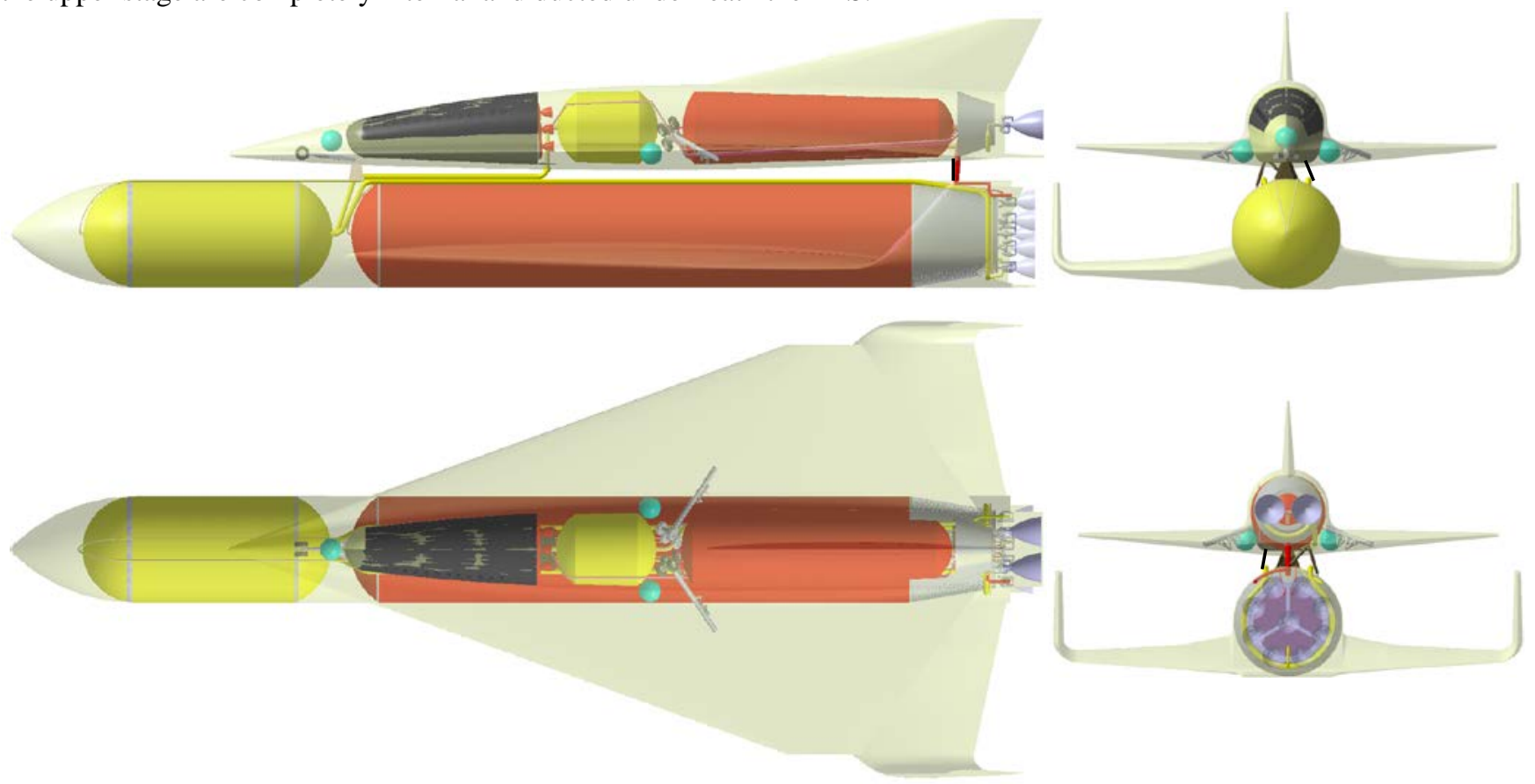

Figure 3: Sketch of latest SpaceLiner 7-3 launch configuration with passenger stage on top and booster stage at bottom position

The main dimensions of the 7-3 booster configuration are listed in Table 1 while major geometry data of the SpaceLiner 7-3 passenger stage are summarized in Table 2.

Table 1: Geometrical data of SpaceLiner 7-3 booster stage

\begin{tabular}{|c|c|c|c|c|c|c|}
\hline length [m] & span [m] & height [m] & $\begin{array}{c}\text { fuselage } \\
\text { diameter [m] }\end{array}$ & $\begin{array}{c}\text { wing leading } \\
\text { edge angles } \\
\text { [deg] }\end{array}$ & $\begin{array}{c}\text { wing pitch } \\
\text { angle [deg] }\end{array}$ & $\begin{array}{c}\text { wing dihedral } \\
\text { angle [deg] }\end{array}$ \\
\hline 82.3 & 36.0 & 8.7 & 8.6 & $82 / 61 / 43$ & 3.5 & 0 \\
\hline
\end{tabular}

Table 2: Geometrical data of SpaceLiner 7-3 passenger stage

\begin{tabular}{|c|c|c|c|c|c|c|}
\hline length [m] & span [m] & height [m] & $\begin{array}{c}\text { fuselage } \\
\text { diameter [m] }\end{array}$ & $\begin{array}{c}\text { wing leading } \\
\text { edge angle } \\
\text { [deg] }\end{array}$ & $\begin{array}{c}\text { wing pitch } \\
\text { angle [deg] }\end{array}$ & $\begin{array}{c}\text { wing dihedral } \\
\text { angle [deg] }\end{array}$ \\
\hline 65.6 & 33.0 & 12.1 & 6.4 & 70 & 0.4 & 2.65 \\
\hline
\end{tabular}

\section{SpaceLiner 7 Structural Design and Analyses}

\section{A. Reusable booster stage (SLB)}

The current SpaceLiner 7 booster geometry is relatively conventional with two large integral tanks with separate bulkheads for LOX and LH2 which resembles the Space Shuttle External tank lay-out. The major additions to the ET are an ogive nose for aerodynamic reasons and for housing subsystems, the propulsion system, and the wing structure with landing gear. The overall size of the booster is reaching significant dimensions of more than $80 \mathrm{~m}$ in 
length, if the ambitious reference mission is to be served. Major geometrical data of this configuration 7-3 are listed in Table 1.

According to the current baseline assumption, the two tanks are part of the load carrying structure and therefore the structural members are placed internally. The structure of the wing follows aircraft convention with ribs to make up the shape of the wing profile and spars to carry the main bending load [20, 23]. Both tanks with an external structural diameter of $8.5 \mathrm{~m}$ carry all major loads and interface thrust to the passenger stage is going through the intertank right in front of the very large LH2 tank with a total internal volume of $2577 \mathrm{~m}^{3}$. Engine thrust and the ground support loads at the launch pad are directed through the conical thrust frame shown in Figure 4 which is connected to the aft-Y-ring of the hydrogen tank.

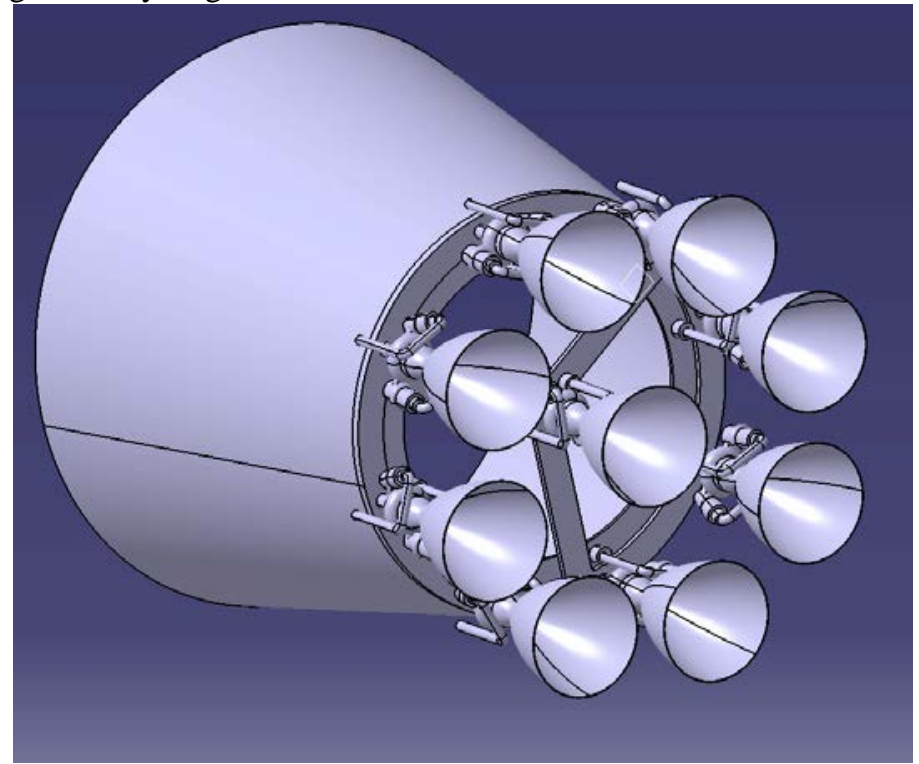

Figure 4: Thrust cone of SpaceLiner 7-3 booster with SLME attached

Structural sizing trade-off studies are currently performed, where the focus is on the identification of optimum structural design solutions rather than on precise mass predictions. The finite element (FE) based parametric structural analysis and optimization tool HySAP (Hypersonic vehicle Structural Analysis Program) [29, 30] is used for this task. The SLB's FE structural architecture model is displayed in Figure 5.

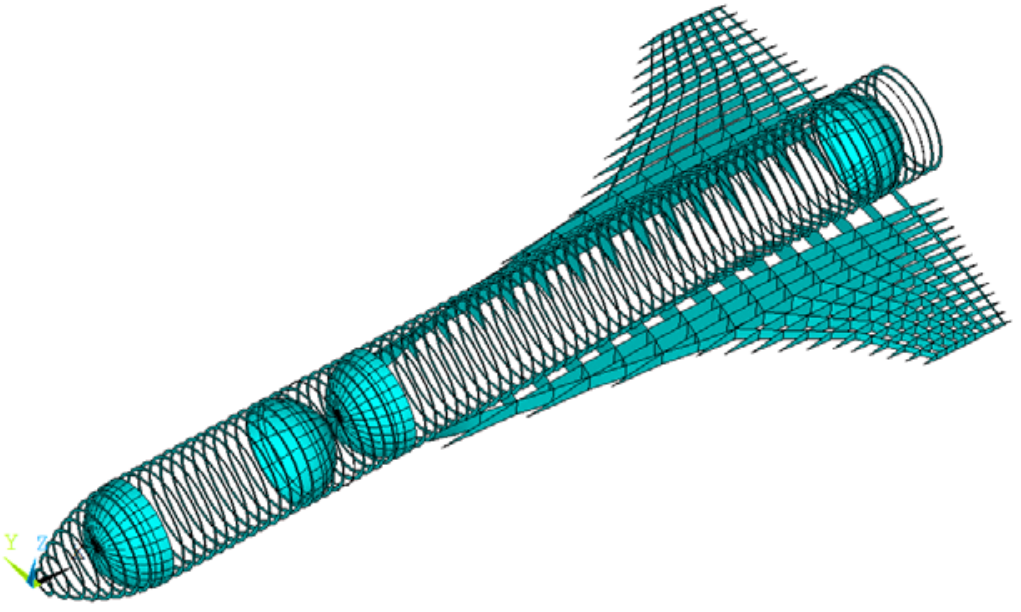

Figure 5: ANSYS FE-model of SpaceLiner 7-3 booster

The baseline structural design utilizes integrally stringer/frame stiffened aluminum lithium (Al-Li) 2195 skins for the "fuselage" (LOX \& LH2 tanks, nose cone, inter-tank-structure, aft skirt), and 2195 honeycomb sandwich panels for the wings. The operating temperature of the structure is depending on the TPS design. Increased acceptable 
temperatures would allow for TPS thickness and hence TPS mass reductions, however, growing structural mass due to material property degradation (strength, modulus) and thermal stresses would have to be faced. To allow for the consideration of these thermal effects during preliminary design studies, a simplification has been made: the structural skins are assumed to operate at an elevated service temperature which is dictated by the particular TPS design, while the internal members (ribs, spars, frames) remain on room temperature level. This is to some extent a worst case scenario as the temperature differences between skin and internal structure members introduce significant thermal stresses.

The blue curve in Figure 6 shows the resulting relative structural masses (normalized to a vehicle structure theoretically operating completely under room temperature conditions) for a representative set of 6 load cases. This design assumes internal tank insulation for both tanks; therefore the tank structure is not subjected to cryogenic temperatures. However, such a design raises concerns as the insulation materials will be in direct contact with the cryogenic fluids, generating compatibility challenges, especially with respect to the reusability requirement. Thus, externally insulated tanks are currently preferred although no choice has been selected yet. The structural mass development for a design with external cryogenic insulation is represented by the red curve in Figure 6. As can be seen, a dramatic structural mass increase with respect to the internally insulated design is to be expected.

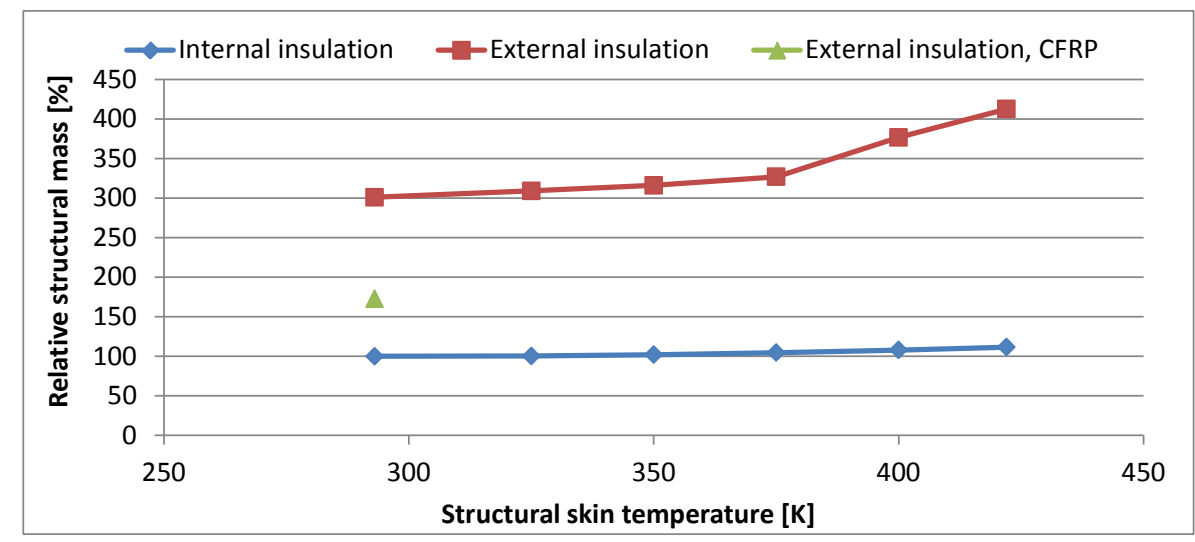

Figure 6: Relative structural masses for booster variants with internal and external tank insulation as function of the structural skin temperature

The explanation for this structural mass increase is the formation of severe thermal stresses at the interface between the "warm" wing and the cryogenic LH2-tank. Figure 7 shows the calculated skin/facesheet thicknesses for an externally insulated tank configuration. The complete LH2 tank cylinder as well as parts of the adjacent wing panels are sized to the maximum allowed thickness of $25 \mathrm{~mm}$.

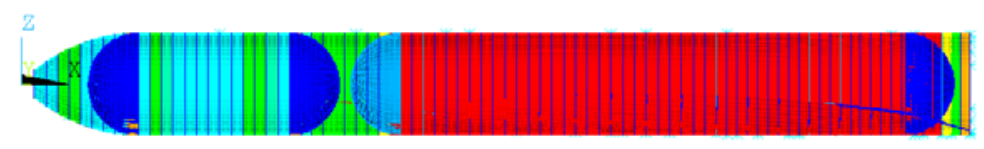

Side view

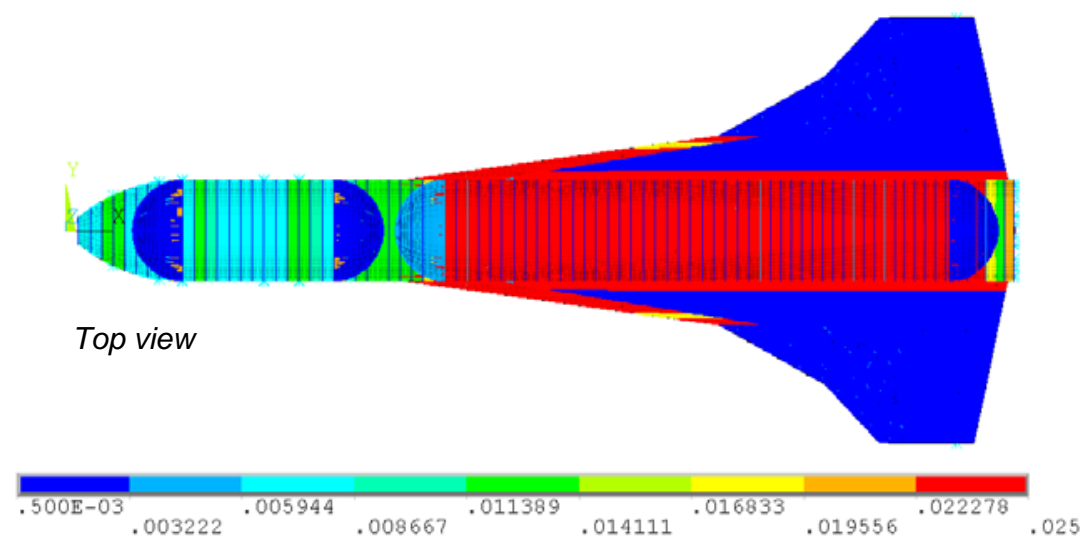

Figure 7: Predicted skin/facesheet thicknesses in [m] for SLB configuration with external tank insulation 
The thermal stress formation and the resulting structural masses are inacceptable for a feasible vehicle design. The utilization of a non-integral tank is a potential design option to reduce these thermal stresses, where LH2 tank and "fuselage" primary structure are separate entities, thus allowing for unconstraint thermal expansion and contraction relative to each other. Such an arrangement is currently under investigation but is not necessarily the optimum configuration in terms of overall system mass and complexity. Other design options include the utilization of structural materials with lower CTE (coefficient of thermal expansion) such as CFRP composites or titanium. Both material groups however suffer from compatibility issues when being in contact with cryogenic LOX or LH2. Although recent developments in the area of thin-ply composites may enable the utilization of CFRP for LH2 tanks [31], it is currently not clear whether this can be achieved for the requirement of multiple and long term reusability.

Nevertheless, a design has been investigated where the vehicle structure including the LH2-tank is made of CFRP composites while the LOX-tank is still made of 2195 aluminum alloy. The estimated structural mass has been added to Figure 6 for a single data point. In fact, the CFRP utilization with external insulation allows for a strong reduction in structural mass compared to the aluminum design with external insulation. However, the structural mass is still high and significantly exceeds the allocated structural mass budget. Consequently, alternative design solutions are currently under investigation, together with a non-integral tank approach. Such alternative solutions include dedicated thermal expansion relieve designs or sliding joints.

\section{B. Reusable Passenger stage (SLP)}

For the structural architecture of the passenger stage, always non-integral tank integration has been assumed in expectation of the severe thermal loads in atmospheric flight beyond Mach 20. Preliminary structural analyses using HySAP have also been conducted for the passenger stage. The considered load cases include $2.5 \mathrm{~g}$ and $-1.0 \mathrm{~g}$ normal acceleration maneuvers with flap deflection, rocket powered ascent where the SLP is still attached to the booster, and landing loads at main gear touch-down. The vehicle structure is an all honeycomb-sandwich design. Stringer stiffening of the fuselage has been investigated as well, but was found to be not competitive in terms of structural mass.

The cut-out in the fuselage necessary for passenger cabin integration (see section V below!) are included in the vehicle's FE-model. Figure 8 exemplarily shows stress resultants in $\mathrm{x}$ - and $\mathrm{y}$-direction in the local panel coordinate systems for the landing load case. The vehicle deflections are exaggerated in the figure. Severe local loads in the cut-out area are obvious. Resultant stress peaks can also be observed at the landing gear positions in the wing due to touch down load introduction.
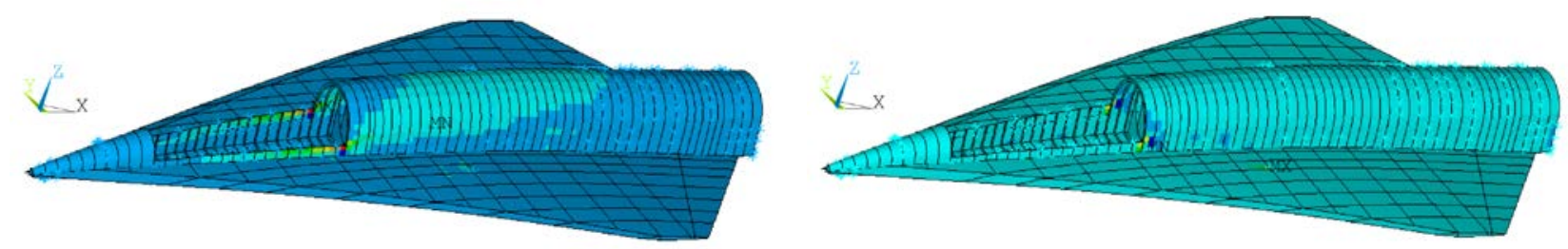

Figure 8: Stress resultants in x-direction (left) and y-direction (right) in local panel coordinate systems for landing load case for SpaceLiner 7-3 passenger stage primary structure

A relative structural mass comparison for different materials is presented in Figure 9. Thermal effects have been considered in a similar way as for the booster. It should be noted that this analysis includes the wing and the fuselage structure while for other structural items such as fin, thrust-frame etc. no structural analysis has been conducted so far. Data are normalized to an Al-Li 2195 structure at $293 \mathrm{~K}$ structural skin temperature. Next to Al-Li 2195, titanium (Ti-6Al-4V heat treated), beryllium based Beralcast (LockAlloy), as well as two CFRP composite materials (IM7-PETI-5, IM7/APC-2) have been considered. IM7/PETI-5 is based on a polyimide matrix [32] while IM7/APC-2 utilizes a PEEK matrix system [33]. Calculation results in Figure 9 show that IM7/APC-2 provides the lightest structural mass. Its operation temperature regime has, however, been limited to $394 \mathrm{~K}$ based on the material data provided in ref. 33. The structural mass of an IM7/PETI-5 based airframe is significantly higher, even higher than that of an Al-Li 2195 structure; but its operation temperature range can be extended to $500 \mathrm{~K}$. The metallic materials feature considerable thermal stress build-ups. This is particularly true for LockAlloy with its extraordinary high elastic modulus. Due to excessive thermal stresses in a primary structure built out of LockAlloy, no converged solution could be found for operation temperatures beyond $350 \mathrm{~K}$. The relatively poor performance of a titanium 
based vehicle structure is due to a large extent result of minimum-thickness considerations. In Figure 9 the relative mass of the passive TPS is also shown as function of the maximum assured skin temperature.

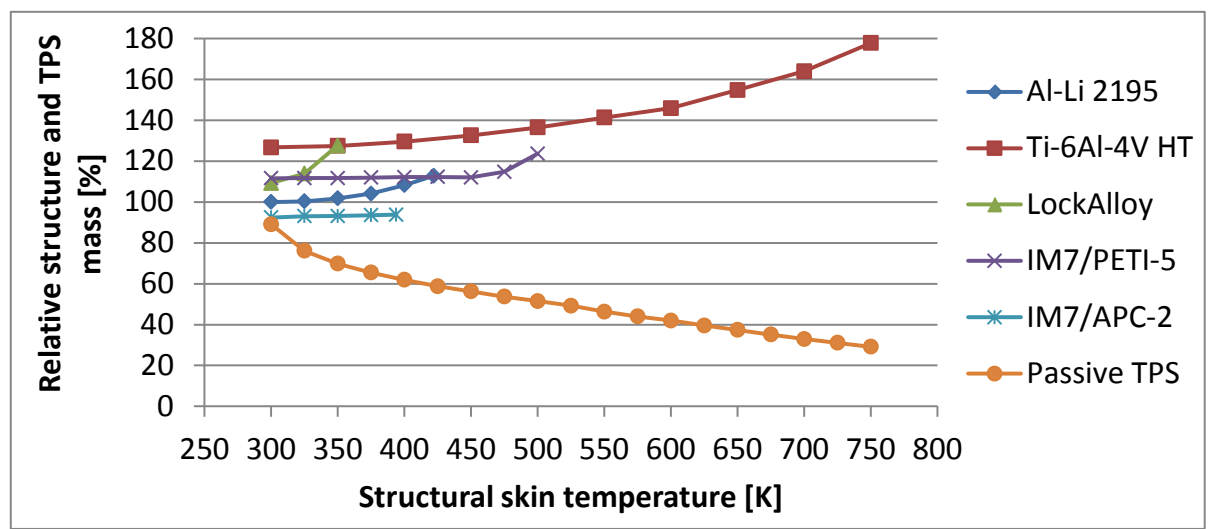

Figure 9: Relative structure and passive TPS masses (wing plus fuselage) for SpaceLiner7 passenger stage as function of structural skin temperature and material selection

The combined structure and passive TPS mass is shown in Figure 10. Note that the presented values of this figure already consider to some extent structural mass penalties due to TPS-integration issues. Thus, they are larger than the sum of the structure and TPS mass trends from Figure 9. An Al-Li 2195 based airframe exhibits a mass minimum at a structural skin temperature of $400 \mathrm{~K}$, titanium in the $500-600 \mathrm{~K}$ range, IM7-PETI-5 at $450 \mathrm{~K}$, and IM7/APC-2 at the maximum considered structural temperature of $394 \mathrm{~K}$. Beralcast (LockAlloy) is no longer included in this comparison.

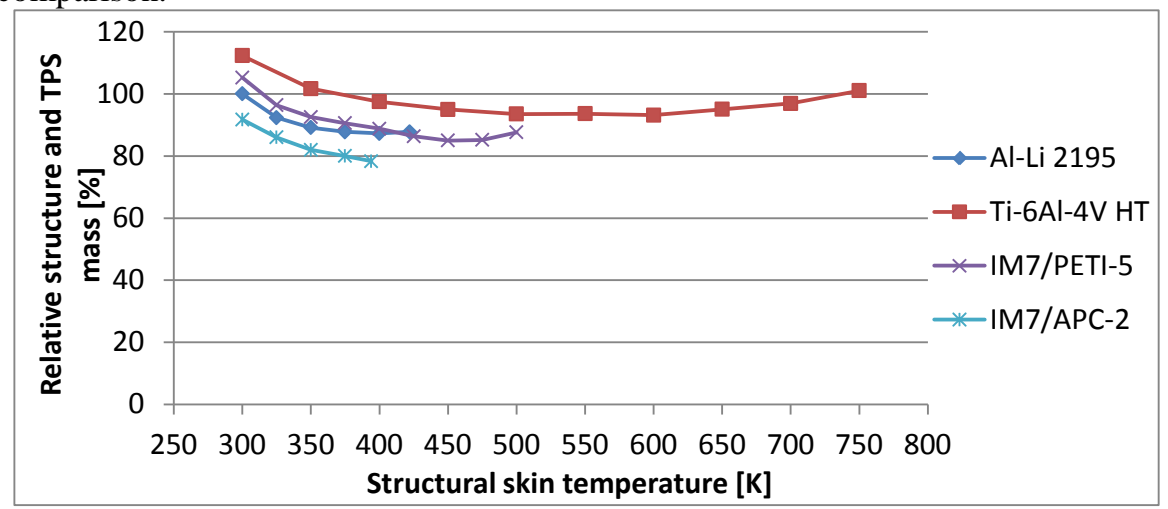

Figure 10: Relative airframe mass as function of the structural skin temperature

Sufficient data from structural trend analyses are available for choosing a reference design of the SpaceLiner passenger stage's primary structure in the near future.

\section{SpaceLiner 7 Aerodynamics and CFD}

The Mach number range of the SpaceLiner's booster and passenger stage both stretches from the hypersonics through the transonic regime to the low speed subsonic landing approach. Aerodynamic data sets have been generated with different numerical tools and an aerodynamic database for preliminary engineering design work has been established [36] for all four SpaceLiner flight configurations: The mated launch vehicle, the booster stage, the passenger stage, and the rescue capsule.

Several technical papers describe the SpaceLiner's aerodynamic shape definition and important research results [13, $15,27,36,48]$.

\section{A. Reusable booster stage (SLB)}

The booster wing (and winglet) airfoils have been selected as modified NPL-EC/ECH cut at trailing edge thickness of $75 \mathrm{~mm}$ [36]. The relative backward position of maximum chord thickness is beneficial for drag reduction in the 
supersonic and hypersonic flow (thus improved L/D) and at the same time allows for better structural efficiency where the largest amount of the aerodynamic lift forces are introduced.

ESA has been calculating the SpaceLiner 7-3 booster stage with Euler CFD. An unstructured grid with several million elements has been generated. The booster separation Mach number of the passenger version's reference mission Australia to Europe is approximately 12.5. After a short ballistic phase the SLB enters the denser atmosphere and decelerates, reaching the maximum heatload around Mach 10 in $50 \mathrm{~km}$. Figure 11 shows the atmospheric entry condition of the booster stage after separation close to its maximum load condition. A critical shock-shock interaction at the outboard leading edge has been revealed. The situation needs improvement of the SpaceLiner booster aerodynamic design of future variants.

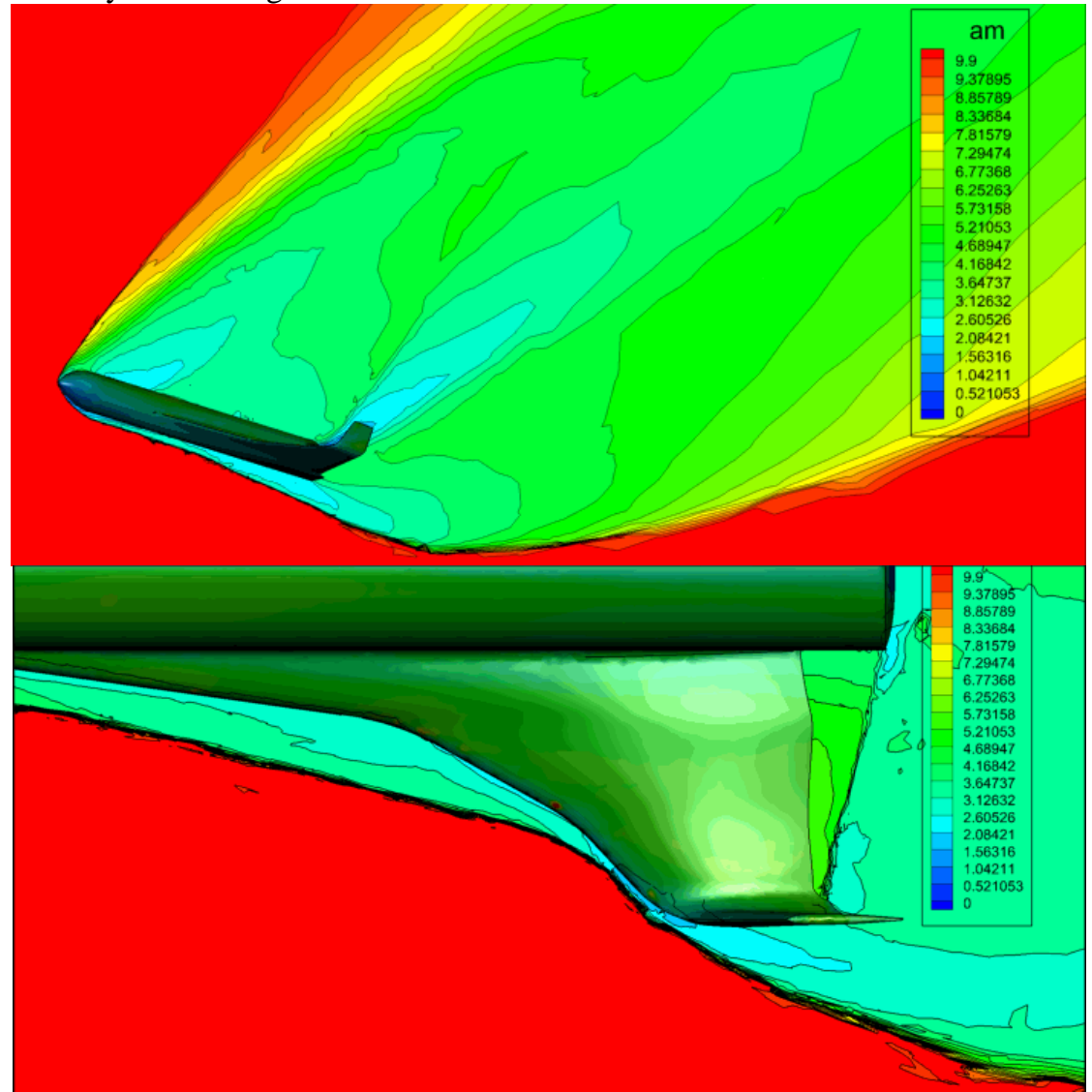

Figure 11: Mach contours of SpaceLiner 7-3 booster stage at $M=10, \alpha=35^{\circ}$ from ESA-ESTEC Euler CFDcalculation

\section{B. Reusable Passenger stage (SLP)}

An extensive early study on the different geometrical options for the optimization of the hypersonic aerodynamic and aerothermodynamic characteristics of the SpaceLiner has been concluded at DLR in 2010 [13]. The SpaceLiner7 aerodynamic shape of the passenger stage results from a fully automated optimization process. In order to consider a wide range of the hypersonic trajectory, three points with different flight Mach numbers (20.1, 13.6, 6.0) and corresponding altitudes were chosen for the optimization [27]. The SpaceLiner 7-3 configuration passenger stage wing airfoils keep a finite minimum thickness at the trailing edges of $50 \mathrm{~mm}$ constant thickness. At the wing's root a modified NACA 66-003.5 is implemented which is cut when the trailing edge thickness reaches $50 \mathrm{~mm}$.

In the context of FAST20XX, ESA in parallel with ELECNOR Deimos contributed CFD analyses for the descent flight to support the maturity of the SpaceLiner concept by calculating the shape of the SpaceLiner 7-1 passenger stage [36, 43]. The performed analyses spanned the entire Mach range $(0.4-18)$ and consisted of perfect gas Euler simulations. An unstructured grid with several million elements had been generated. 
The appraisal of the results obtained included the acknowledgement of deficiencies in the Euler subsonic-transonic modelling, whilst the level of accuracy of the supersonic and hypersonic regime was deemed appropriate. After the end of FAST20XX, subsonic/transonic modelling has been improved by mesh refinement resulting in better convergence behavior. Supersonic flow modelling is aiming at sonic boom prediction and efficiency increase for hypersonic modelling. All topics involve an improved control of the mesh refinement procedures. Surface streamlines confirm the presence of a strong vortex (Figure 12). Flowfield anisotropic refinement enhances the capture of such features.

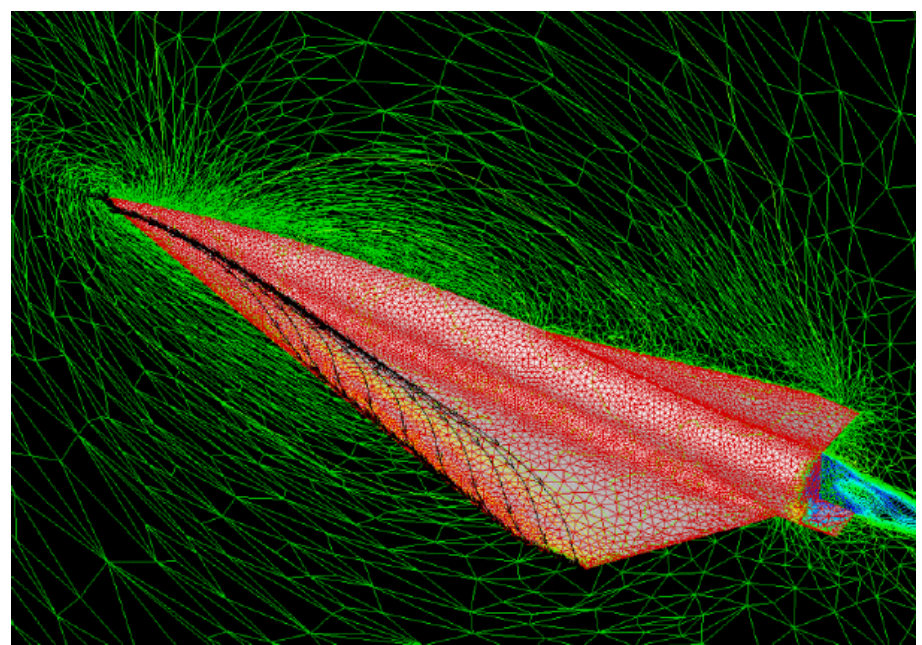

Figure 12: Strong vortex at SpaceLiner 7-3 passenger stage leading edge in subsonics obtained from ESAESTEC Euler CFD-calculation with anisotropic mesh refined flowfield

The SpaceLiner 7 passenger stage achieves without flap deflection an excellent hypersonic L/D of 3.5 up to M=14 assuming a fully turbulent boundary layer. The laminar-turbulent transition is assumed occurring at an altitude of 58 $\mathrm{km}$ which is around Mach 18 [36]. Impact of the finite trailing edge introduced in version 7-3 on aerodynamic efficiency is negligible.

Experiments of the 7-3-configuration are planned in the windtunnels TMK and H2K at DLR-Cologne. A model in scale 1:158 with different wingflap $\left(+/-20^{\circ}\right)$ and bodyflap $\left(10^{\circ}\right)$ deflections has been manufactured. The model is shown in Figure 13 in an early run in hypersonic flow condition.

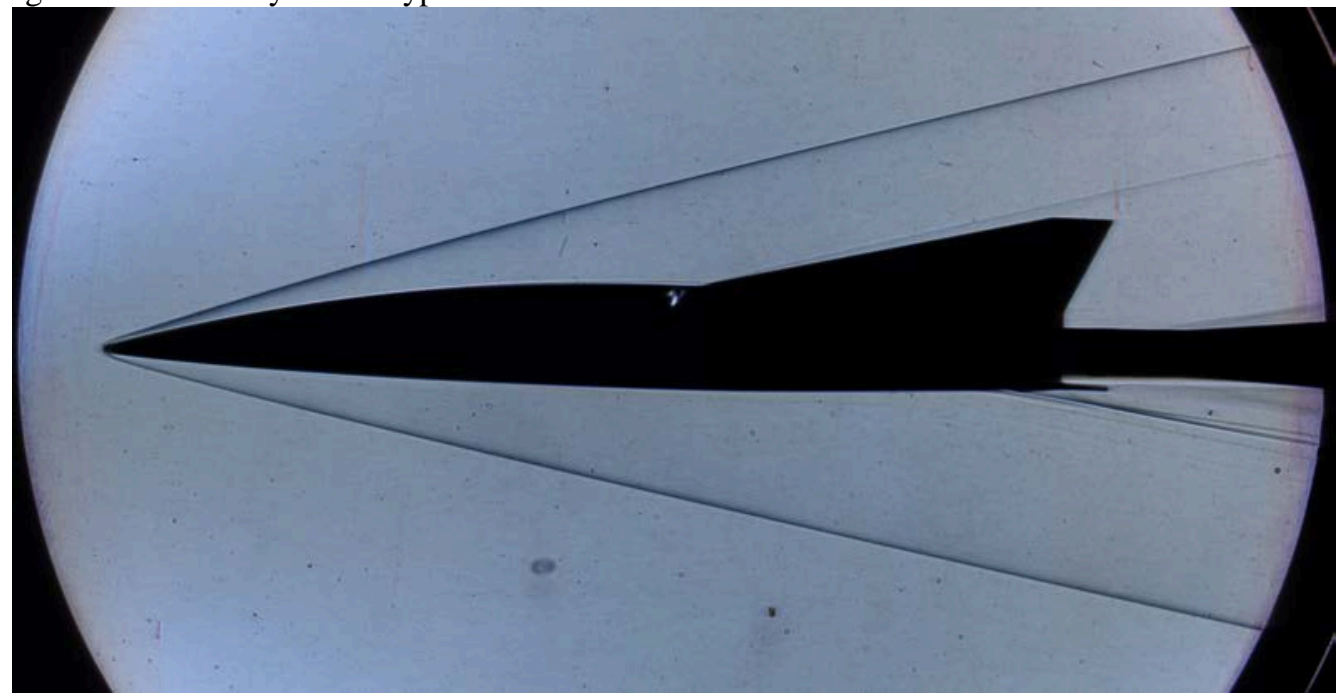

Figure 13: Schlieren image of the SpaceLiner 7-3 passenger stage model in DLR hypersonic windtunnel H2K $\left(M=5.3, \alpha=2^{\circ}, \operatorname{Re}=16 \cdot 10^{6} \mathrm{~m}^{-1}\right)$

In some areas of the SpaceLiner passenger stage (leading edge and nose) the heatflux and temperatures exceed those values acceptable by CMC used in the passive TPS [21, 35, 37]. Already early in the project, transpiration cooling using liquid water has been foreseen as a potential option for solving the problem [2, 23, 11, 15]. In FAST20XX this 
innovative method has been experimentally tested in DLR's arc heated facility in Cologne using subscale probes of different porous ceramic materials [16]. A water storage tank system, a feedline manifold including control and check-valves and some bypass and redundancy lines were sized for accommodation inside the SpaceLiner volume [46].

Besides the overall promising results also some technical challenges of the active transpiration cooling system have been detected in the FAST20XX-investigations. Precise controllability of the water flow through the porous ceramic media has been found difficult [47]. The experiments sometimes were running into over or under supply of water which could not be recovered within the same experimental run. A more sophisticated supply system would be needed in a flight vehicle. Another concern is the fact that the gas flow from the coolant might trigger early boundary-layer transition. As a consequence, some areas of the passive TPS might need to be reinforced. Therefore, the active transpiration cooling of leading edges and nose is still the reference design option but could once be replaced by other means of active cooling [46, 47].

\section{SpaceLiner 7 Cabin and Rescue System}

\section{A. Baseline Cabin and Requirements}

The passenger cabin of the SpaceLiner has a double role. Providing first a comfortable pressurized travel compartment which allows for horizontal entrance of the passengers, the cabin in its second role serves as a reliable rescue system in case of catastrophic events. Thus, the primary requirements of the cabin are the possibility of being firmly attached late in the launch preparation process and fast and safely separated in case of an emergency. Overall length of the capsule for 50 passengers (without separation motors) is $15.6 \mathrm{~m}$ and its maximum external height is 5.6 $\mathrm{m}$.

The capsule should be able to fly autonomously back to Earth's surface in all separation cases. The abort trajectories are primarily influenced by the mass of the capsule and the aerodynamic performance with the most important subsystems being the separation motors, the thermal protection system (TPS), and the structure. These three subsystems have been investigated and sized for function, performance, and mass.

Four critical flight points have been chosen to simulate the abort trajectory to demonstrate the SpaceLiner7 capsule is able to fly safely back to Earth during any perceived abort scenario [28, 40]. The separation motors are designed to separate the capsule from the orbiter at most demanding launch-pad abort, without exceeding recommended maximum acceleration limits. The SRM must provide a high acceleration in a very short period of time. Due to severe geometry constraints, it has been decided to utilize a five motor configuration. Each motor has an approximate sea-level thrust of $870 \mathrm{kN}$ and a burn time of almost $2 \mathrm{~s}$.

A fundamental requirement for the design of the rescue capsule is its integration in the front section of the passenger stage as shown in Figure 14. The capsule should be separated as easily and quickly as possible. Therefore, it cannot be an integral part of the fuselage structure, however, its upper section is conformal with the SpaceLiner's fuselage while the lower side is fully protected by the fuselage bottom structure.

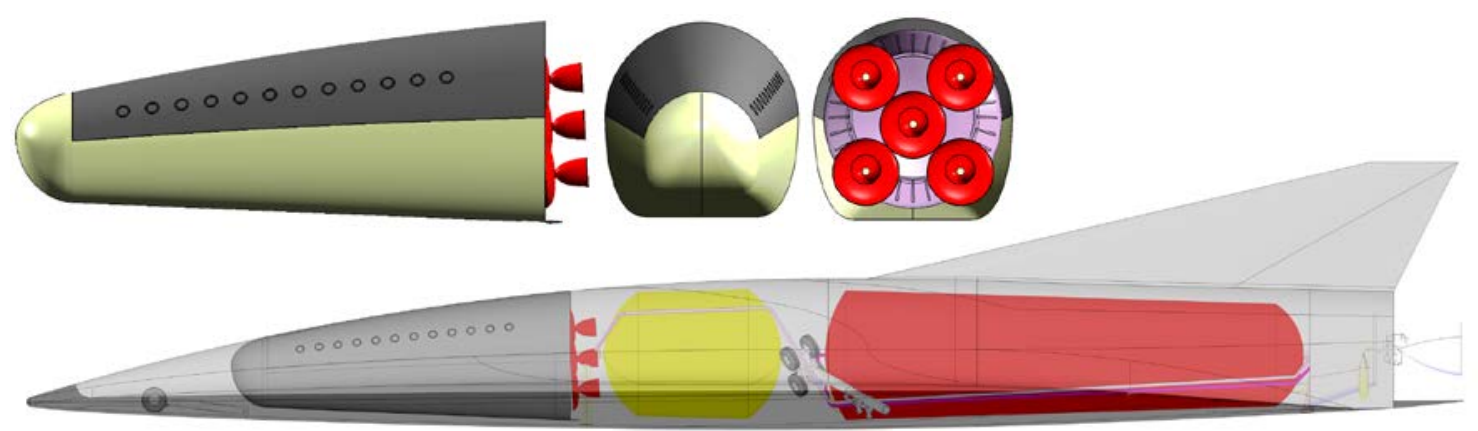

Figure 14: SpaceLiner rescue capsule (at top in side, fwd. and aft view) and integration into mothership version 7 (side view only) 
The capsule can be subdivided in a pressurized cabin of conical shape and an outer aerodynamic shell formed by the Thermal Protection System (TPS) and which provides space for housing several non-pressurized subsystems [35, 37]. The TPS of the SpaceLiner7 capsule is required to withstand several different heat load conditions driven by the different nominal and abort cases it encounters. During nominal flight, the capsule is considered part of the orbiter.

The current requirement of capsule separation being feasible at any flight condition and attitude is highly challenging from a technical point of view. Analyses revealed some critical issues to be addressed in order to improve the safe functionality of the cabin rescue system. Alternative capsule integration concepts have been proposed and technically analyzed [40]. However, each of the explored design options is linked to severe challenges and drawbacks. Further investigations are necessary to find a promising and reliable system.

\section{B. Capsule Subsystems Definition}

A preliminary design for the capsules main subsystems has been elaborated within the HYPMOCES project. This includes the body flaps, deployable rudders, the parachute system for transonic stabilization and landing, the electromechanical actuators and their batteries, and the reaction control system (RCS). Compared to earlier cabin designs $[28,35,40]$ the previously single bodyflap has been replaced by double flaps and two deployable control fins have been added on the upper surface. Both measures are significantly improving flight controllability and stability in a major portion of the required domain.

The flap design developed by Aviospace in Turin and presented in Figure 15 (left) matches the constraints induced by the demanding thermo-mechanical environment experienced during hypersonic flight. The moving part is an open box with ribs made out of $\mathrm{C} / \mathrm{C}-\mathrm{C}-\mathrm{SiC}$ as a monolithic object showing small thermal gradients with reduced deformations and stress. The components of the flap actuation system are scaled with the IXV flap actuator design successfully flown in 2015. The capsule's flap control system architecture takes inspiration from the IXV design which is characterized by 2 electro-mechanical actuators with 2 flaps in the operative range from maximum $\left(+15^{\circ}\right)$ to minimum $\left(-10^{\circ}\right)$ deflection. The EMA of the VEGA P80 TVC is chosen with some stroke adaptations to fit with the flap actuator power requirements and in a similar way the batteries are pre-sized.

Adding two symmetrically attached rudders in the aft section of the capsule is significantly enhancing its flying qualities in case of autonomous flight. However, the rudders should be stored in a position not disturbing the outside flow when the capsule is integrated into the passenger stage during nominal flight. Therefore, in this case the rudder is inside a cavity in the TPS outside of the pressurized section with the external vehicle surface continuous and smooth. A special design must be implemented to protect the vessel under the cavity and to reduce the heat flux and vortex in this area when the rudder is deployed. A flexible, morphing design has been proposed in the HYPMOCES project. The rudder as designed by Aviospace (shown in Figure 15 at right) is completely made of ceramic material. A monolithic object allows having an overall uniform temperature with small thermal gradient and hence reduced deformations and stress. The internal skeleton and the external panels are made of C/C-SiC, while the hinges are protected by Saffil layers. Saffil Fibers contain $95 \%$ to $97 \%$ alumina and are manufactured by a novel solution spinning process.
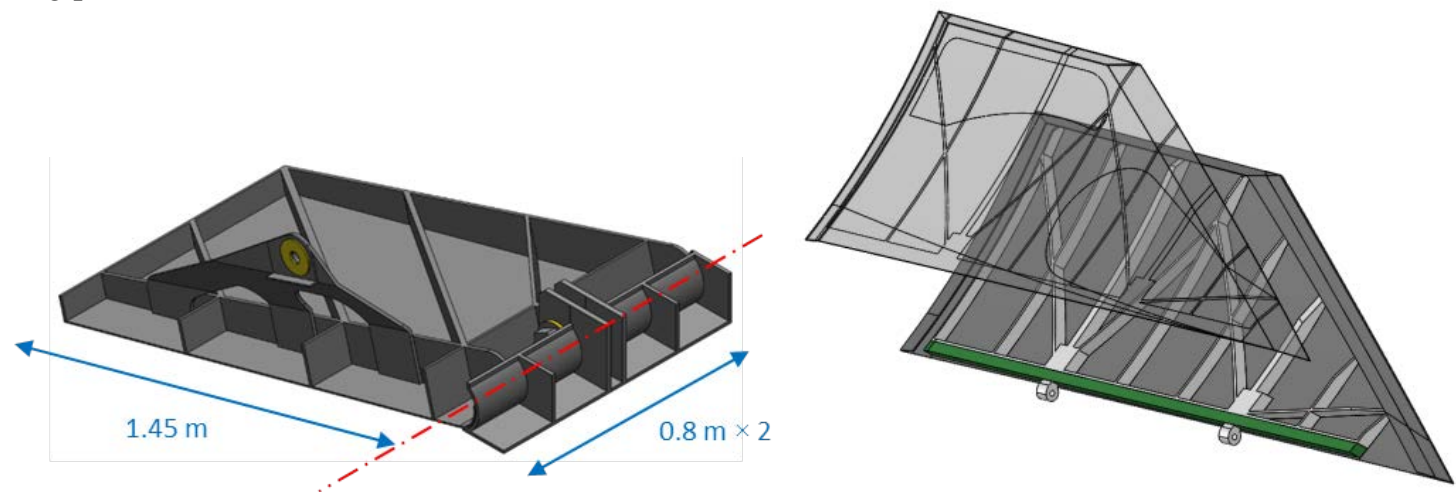

Figure 15: Flap (left) and rudder (right) designed by Aviospace

A preliminary design for the RCS has been performed and three maneuvers are identified as cases of interest: compensation of potential thrust imbalance caused by the separation rocket motors, roll maneuver of cabin, stabilization of flight in nominal, almost exo-atmospheric conditions when the capsule is integrated within the 
passenger stage. The preferred RCS choice is characterized by 2 clusters of thrusters located in the rear part of the capsule. Each cluster provides a thrust of $3 \mathrm{kN}$ along each of the double axis for a total delivered thrust of $12 \mathrm{kN}$. This architecture allows performing quick maneuvers and is characterized by sufficient volume available also for implementing larger thrusters. A non-toxic bi-propellant combination is desirable for passengers' safety and ease of handling and this precludes the use of any variant of hydrazine. The combination $\mathrm{H} 2 \mathrm{O} 2$ (90\%) - kerosene is chosen because of its storability for months, potential hypergolic ignition by additives, and its non-toxic behavior. From an operational standpoint the storability is especially attractive due to the fact that once the tanks are filled, multiple flights can be performed without needing to empty or refuel them. The pressure-fed RCS tank architecture is characterized by a shared system of tanks connected close together, ensuring redundancy at very low mass penalty.

Parachutes are assumed to be deployed and operate in a certain altitude-Mach-box to decelerate the capsule during the final landing phase. The SpaceLiner capsule parachute system is likely a combination of supersonic stabilization chute which allows safe deceleration through the transonics and subsequent subsonic gliding by parafoil. More detailed analyses will be required for any concept down-selection.

The estimated masses (Table 3) are about 25.5 tons for the dry capsule (reference SpaceLiner 7-3), about $7600 \mathrm{~kg}$ for the passengers, crew and luggage, and $3800 \mathrm{~kg}$ for all propellants of separation motor, retro-rockets and RCS.

Table 3: Mass data of SpaceLiner 7-3 passenger capsule

\begin{tabular}{|c|c|c|c|c|c|c|}
\hline $\begin{array}{c}\text { Structure } \\
{[\mathrm{Mg}]}\end{array}$ & $\begin{array}{c}\text { Propulsion } \\
{[\mathrm{Mg}]}\end{array}$ & $\begin{array}{c}\text { Subsystems } \\
\text { including } \\
\text { cabin }[\mathrm{Mg}]\end{array}$ & TPS $[\mathrm{Mg}]$ & $\begin{array}{c}\text { Total dry } \\
{[\mathrm{Mg}]}\end{array}$ & $\begin{array}{c}\text { Total fluid \& } \\
\text { propellant } \\
\text { loading }[\mathrm{Mg}]\end{array}$ & $\begin{array}{c}\text { GLOW incl. } \\
\text { passengers \& } \\
\text { payload }[\mathrm{Mg}]\end{array}$ \\
\hline 9.4 & 0.9 & 10 & 5.2 & 25.5 & 3.8 & 37.2 \\
\hline
\end{tabular}

\section{CFD of Capsule Reentry Flight}

Significant efforts have been conducted by ONERA within the HYPMOCES project to determine the general aerothermodynamics environment of the vehicle. In particular the work aimed at performing a global assessment of the aerodynamic coefficients and wall heat fluxes encountered by the rescue cabin, depending on local conditions, as well as to identify the critical flight points from an aerothermodynamics point of view [39].

The unstructured meshes of the considered geometries have been generated with CENTAUR software. According to the configuration, 3D grid comprises between 10 and 26 millions of mesh cells (tetrahedral, prisms, hexahedral). Prisms levels have been established nearby the wall to properly capture heat transfer (Figure 16). Several zones including the shock and the shock layer have been refined to correctly capture the shock, the aftbody recirculation zone and phenomena occurring in the flap region (hexahedral box in Figure 16), such as flow separation/reattachment or possible shock interactions.

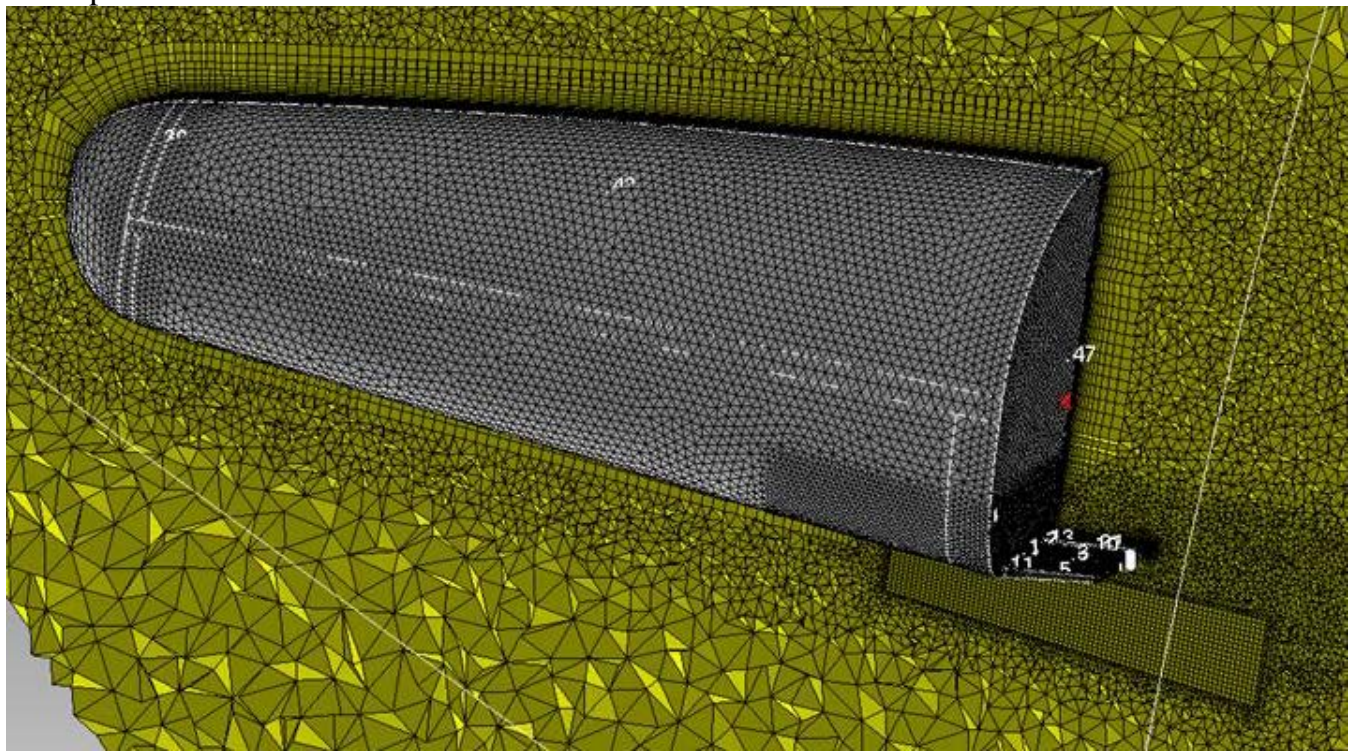

Figure 16: Example of 3D unstructured mesh of the SpaceLiner capsule as defined by ONERA 
CFD computations have been conducted for the most extreme aerothermal conditions when the capsule separated close to SpaceLiner MECO subsequently reaching its atmospheric entry peak heat load (Figure 17). Approximately $1000 \mathrm{~s}$ in its autonomous flight the capsule arrives at this trajectory point at Mach 20 in $57.8 \mathrm{~km}$ [40]. The ONERA unstructured 3D Navier-Stokes solver CHARME (Navier-Stokes solver from the multi-physics CEDRE platform) is used assuming chemical non-equilibrium in the flow with a 5-air species chemical model based on Park's kinetics. The Navier-stokes equations have been resolved with a second-order finite-volume discretization in space, with the flux vector splitting AUSM+ scheme associated to a VanLeer limiter. No turbulence model has been assumed. The walls of the full geometry are considered as fully catalytic with a total emissivity value of 0.8 . The wall heat flux is then calculated assuming radiative equilibrium allowing temperature estimate. Non-catalycity wall process has got a significant effect on wall heating since the stagnation maximum heat flux is almost divided by a factor 1.7 from 678 $\mathrm{kW} / \mathrm{m}^{2}$ for a catalytic wall value to $395 \mathrm{~kW} / \mathrm{m}^{2}$ for a non-catalytic one.
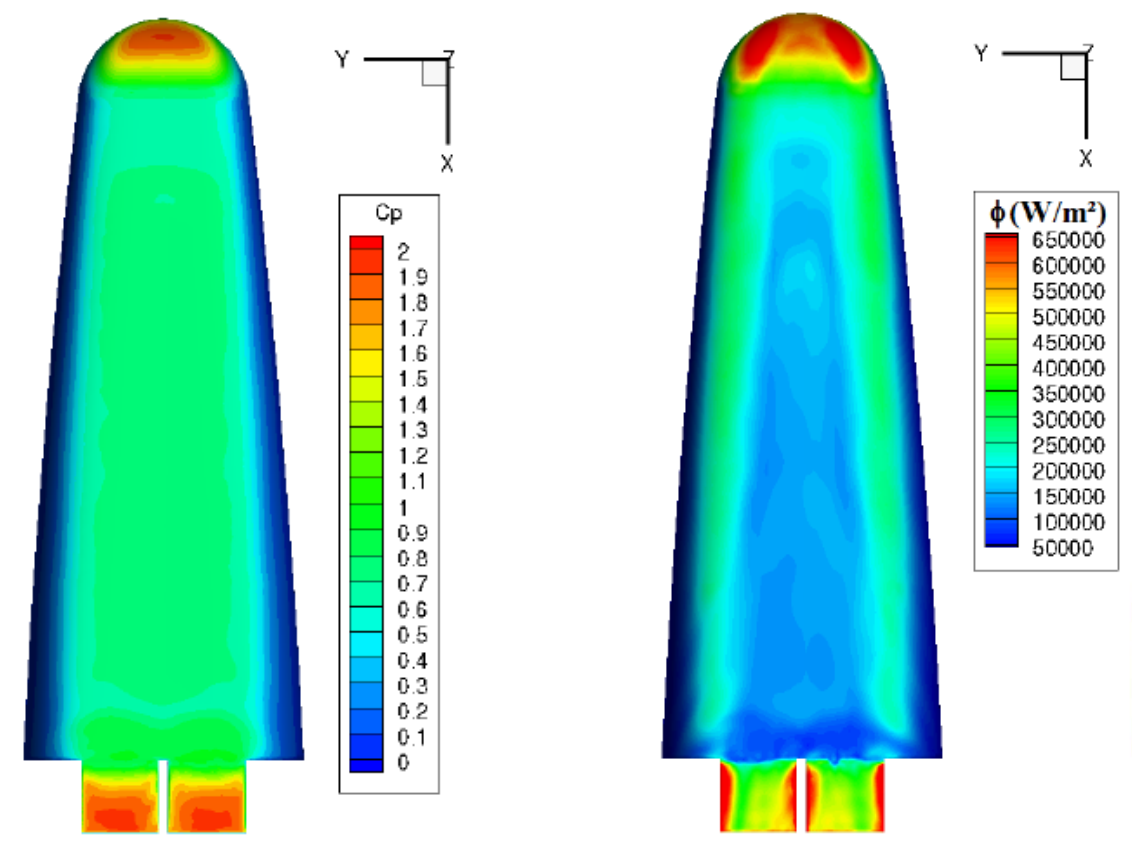

Figure 17: Lower surface of SpaceLiner capsule $\left(M=20,57.8 \mathrm{~km}, \alpha=35^{\circ}\right.$, flap deflection $\left.15^{\circ}\right)$ with pressure coefficient (left) and heat flux (right) calculated by ONERA

Within the HYPMOCES project also micro-aerothermodynamic phenomena have been investigated for the capsule including protuberances like steps and gaps, cavities, stiffeners for flaps, etc. For this purpose the refined mesh of the complete geometry is a hybrid 3D mesh (tetrahedral and prisms) made of 32 million nodes and 90 million elements. The mesh has been designed and refined to comprise the bow shock into the prism zone, as well as the aftbody recirculation zone and detachment/reattachment phenomena occurring in the flap region. CFD computations of the complete geometry have again been conducted with the ONERA unstructured Navier-Stokes solver CHARME using a chemical non-equilibrium model based on Park's kinetics to consider real gas effects occurring. No turbulence model has been employed since laminar status of the flow is expected at Mach 20 and at $57.8 \mathrm{~km}$ altitude.

Windward gaps inserted into the TPS material have a significant influence on the flow topology on the flaps. The gaps are located close to the nose and drive the streamlines up to the flaps where they induce significant heterogeneous flow detachment (Figure 18 top). The temperature of the separation and re-attachment flow can reach almost $5000 \mathrm{~K}$ in the stagnation zone. The temperature at the wall will be cooler although re-attachment always induces high heating conditions. On the leeward side of the flaps small and heterogeneous recirculation zones develop between the hinges (Figure 18 bottom). 


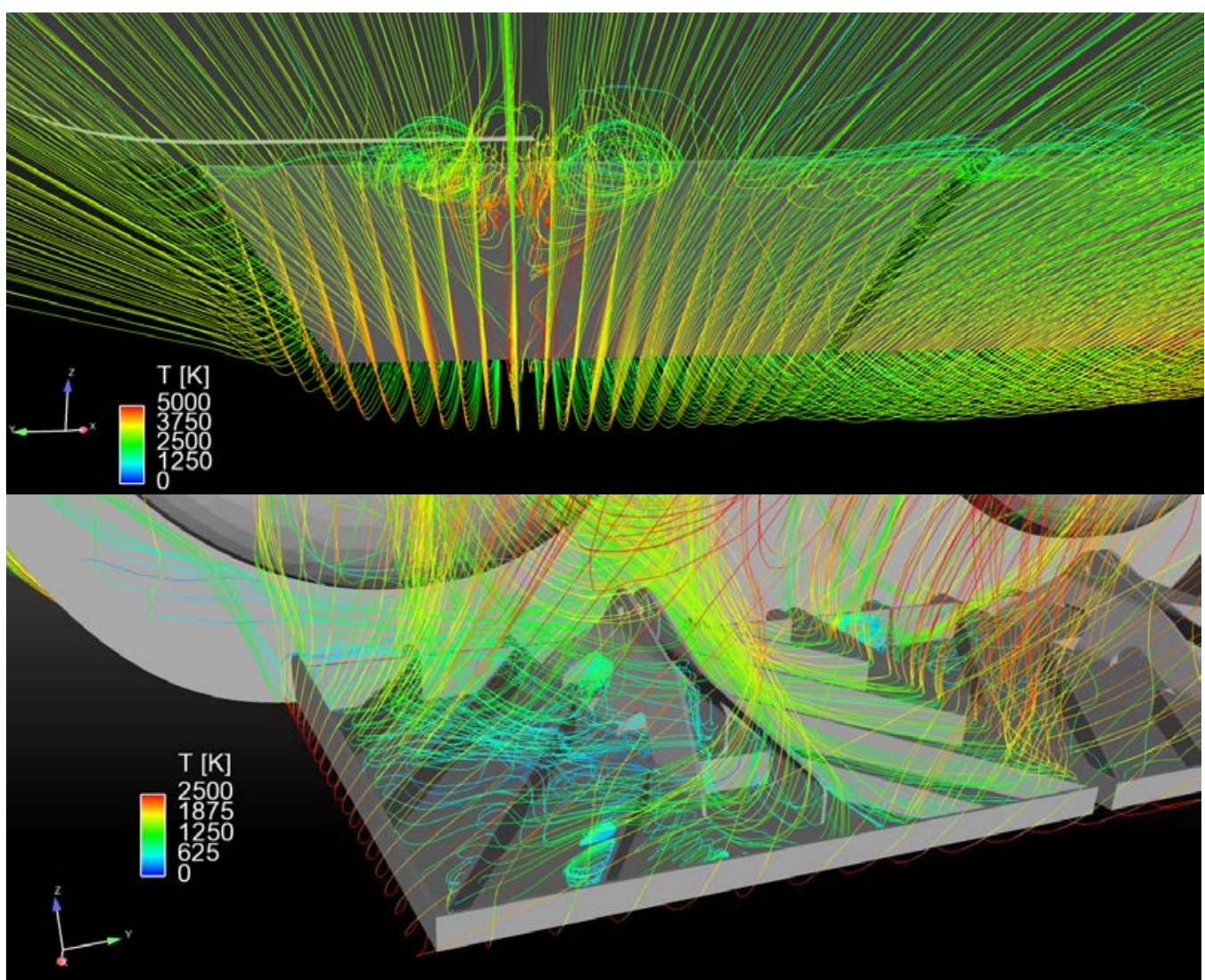

Figure 18: Temperature of the flow (colorized streamlines) in the flaps area of detailed capsule geometry $\left(M=20,57.8 \mathrm{~km}, \alpha=35^{\circ}\right.$, flap deflection $15^{\circ}$ ) windward side (top) and back side (bottom) calculated by ONERA

\section{Morphing structures in Hypersonic flow studied in HYPMOCES project}

A highly innovative investigation on design options to improve the capsules' flight performance after separation has been performed in the European Commission funded FP7-project HYPMOCES (HYPersonic MOrphing system for a Cabin Escape System) aiming to investigate and develop the technologies in the area of control, structures, aerothermodynamics, mission and system aspects required to enable the use of morphing structures [38, 39]. The project was led by DEIMOS Space S.L.U. with participation of Aviospace, ONERA, and DLR-SART.

A multidisciplinary design approach has been successfully introduced since the beginning of the project to achieve a satisfactory design. This has been possible thanks to the introduction of a Concurrent Engineering Session in the very early phase of the project where all the partners contributed actively in the project objectives [41] and by continuous interactions among the team experts during the full 2 years project duration. From an initial trade-off of conceptual designs two preliminary design solutions (one baseline and one backup CES morphing system) were designed as an optimum equilibrium of conflicting objectives among the different disciplines involved, namely: mission analysis, flying qualities, GNC, aerodynamics, aerothermodynamics, structure, mechanisms, and system.

Inflatable as well as rigid deployable wing options have been studied. The baseline design is inflating its lower section after safe separation in order to increase the flat lower surface for increased lift in hypersonic flight enabling better gliding range. The shape of the capsule's lower side before its inflation is compact for storage inside the passenger stage and similar to that shown in Figure 14. The fully inflated lower section and capsule with deployed rudders and deflected bodyflaps are visible in Figure 19. 

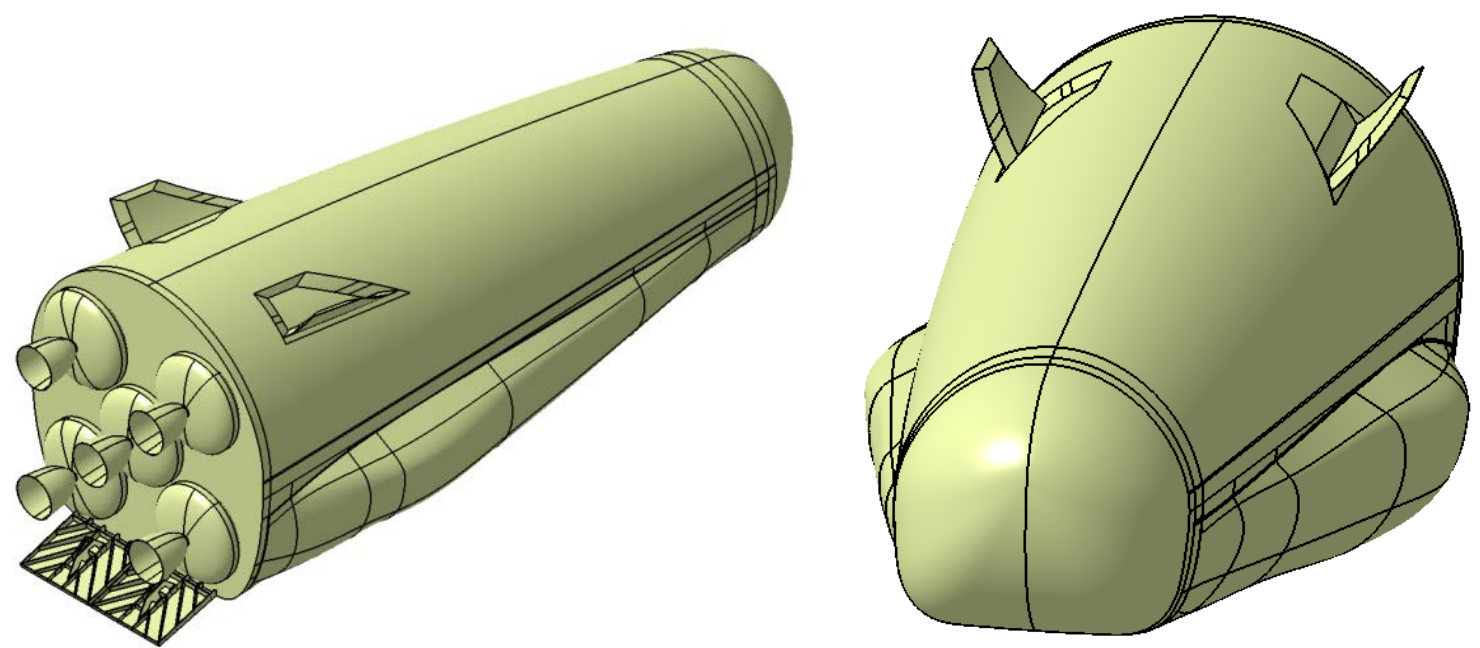

Figure 19: SpaceLiner capsule option with inflatable morphing lower section and deployable fins

The challenges in designing the inflatable morphing structure are finding a membrane material of sufficient flexibility to be easily stowed, rapidly deployed and then being stiff enough to keep a defined external shape in varying flow conditions. As to be used in hypersonics, the material needs to withstand severe aerothermal loads and temperatures. All these design tasks were addressed by Aviospace in close cooperation with the HYPMOCES project partners. The preferred membrane choice is a composite design with several layers of Nextel, Pyrogel, carbon fiber, and Saffil. The thickness of the membrane is different on the windward and leeward side. The driving mechanism of the morphing motion is a system of eight airbags on each side as shown in Figure 20. These bags are to be inflated by commercially available solid gas generators.

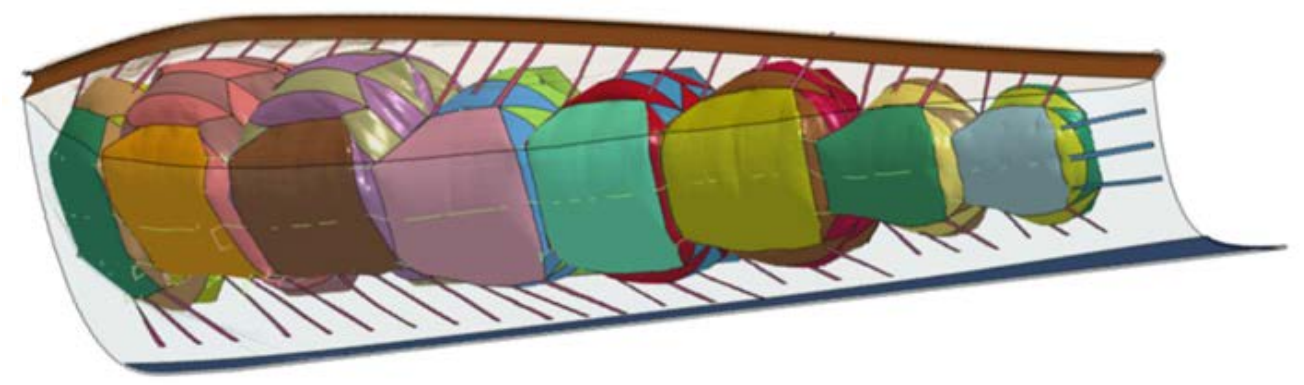

\section{Figure 20: Deployed bags' final design (Aviospace)}

As the membrane is flexible but is not extensible, a part of the membrane is folded into a cavity of the capsule before the deployment and it is blocked in stowed position by a mechanical subsystem. The deployment sequence of $2 \mathrm{~s}$ duration has been simulated by Aviospace using sophisticated numerical tools and a feasible technical solution was demonstrated.

Cutting edge research has been accomplished in the fields of aerothermodynamics based on the ONERA unstructured 3D Navier-Stokes solver CHARME. The flow around the capsule forms a major recirculation zone in the vehicle's wake. The flow temperature of the recirculation zone can reach almost $5000 \mathrm{~K}$ at specific locations where the shear layers gather and the wake shock begins. 


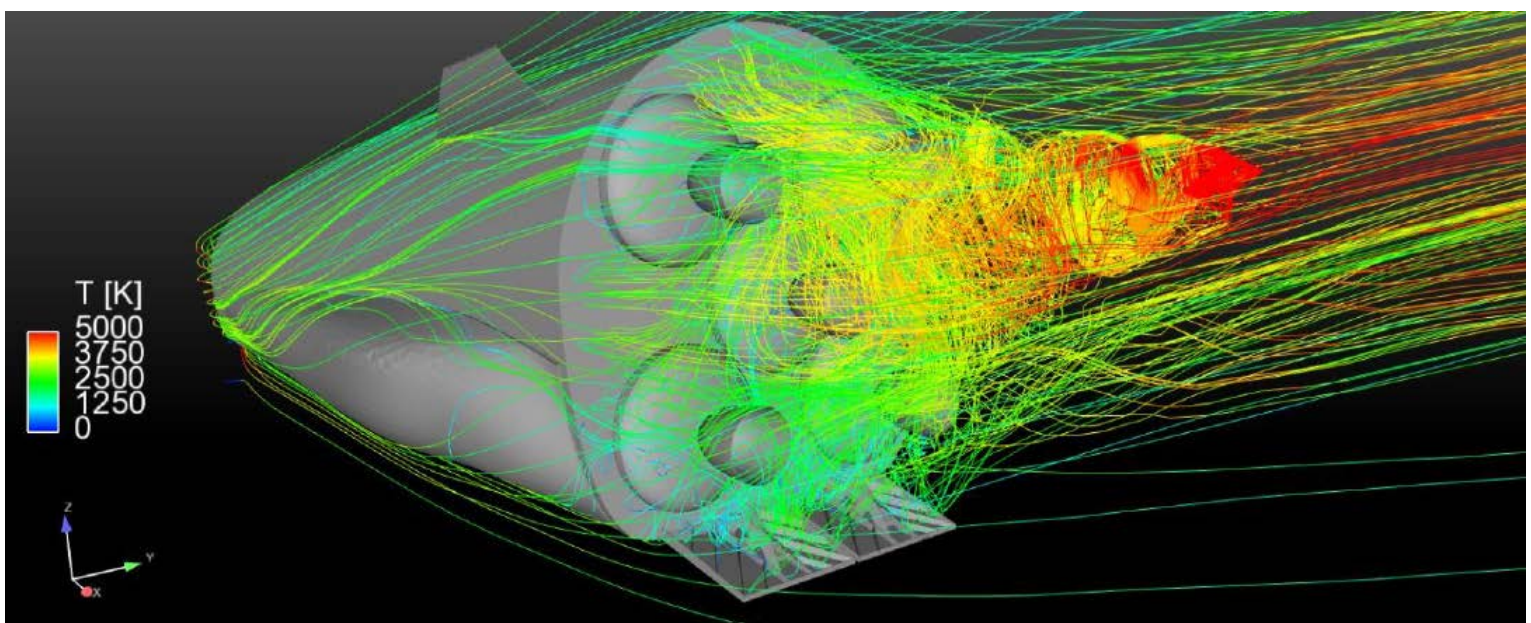

Figure 21: Temperature in the wake flow (colorized streamlines) of detailed capsule geometry (M=20, 57.8 $\mathrm{km}, \alpha=35^{\circ}$, flap deflection $15^{\circ}$ ) from CFD-simulation of ONERA

Wall catalycity has a well-known strong effect on heat transfer and hence surface temperatures. A configuration where the nose and the inflatable membrane are assumed with fully non-catalytic wall and the rest of the vehicle surface considered as fully catalytic has been simulated. The heat flux on the morphing membrane is dramatically reduced in case of non-catalytic behavior, supporting the feasibility of the concept.

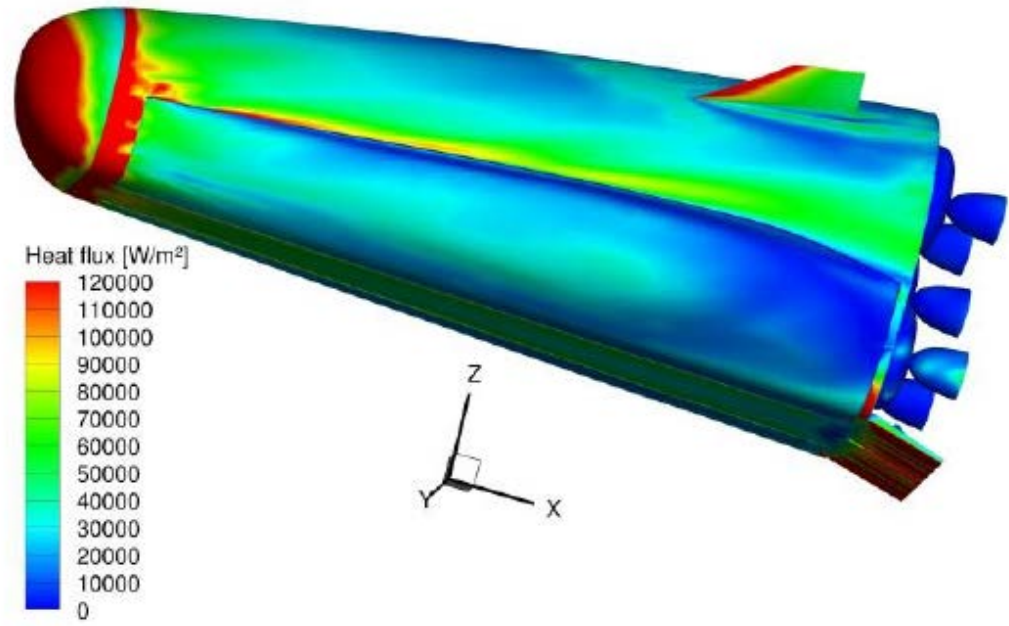

Figure 22: Heat flux distribution on capsule geometry with non-catalytic nose and membrane $(M=20,57.8$ $\mathrm{km}, \alpha=35^{\circ}$ ) from CFD-simulation of ONERA

The detailed CFD results produced by ONERA have been used by DEIMOS Space as anchor points for the fitting of a full aerothermodynamic database, covering the extensive range of flight conditions (Mach, angle of attack, angle of sideslip, flaps deflections) where the vehicle is expected to fly. Based on this input, advanced multidisciplinary optimization tools [44] focused on the tightly coupled areas of mission analysis, Flying Qualities and GNC have been applied by DEIMOS Space to support the identification of optimum vehicle design solutions (center of gravity and aerodynamic surfaces sizing), optimum trajectory and events (morphing activation point) and optimum control profiles (trim line, flaps deflection, RCS use) along the full hypersonic flight regime from separation down to Mach 3. The results obtained indicate that morphing implies a rather quick ( $\sim \mathrm{s})$ change in the external aerodynamic forces and moments, resulting in a reconfiguration of the aerodynamics and mass properties during morphing. These are to be controlled by the GNC with advanced robust control techniques already been successfully tested [45].

The principal feasibility and flyability of the morphing structure concept has been demonstrated by numerical simulations. The maximum hypersonic L/D-ratio of the capsule is increased by approximately $20 \%$ in case of the morphing design compared to the standard configuration. The additional mass of the morphing structure and of related sub systems is approximately $900 \mathrm{~kg}(+3.4 \%$ of empty weight) without considering a potentially necessary 
resizing of the separation motors. This additional mass and system complexity is to be justified by significantly improved passenger safety (due to the possibility of reaching a landing point closer to the infrastructure for passengers rescue operations).

\section{SpaceLiner 7 System Masses}

The SpaceLiner mass budget is constantly tracked; however, the mature status of the configuration 7 usually shows only minor changes. System margins of $14 \%$ (12 \% for propulsion) are continuously added to all estimated mass data despite more and more detailed vehicle and subsystem design. This relatively conservative approach is chosen in order to ensure a robust development phase of this advanced vehicle with ambitious safety and reusability requirements.

The preliminary structural sizing of the booster fuselage resulted in a significant increase in the structural mass of the large integral LH2-tank. Overall booster stage mass is slightly below $200 \mathrm{Mg}$ (Table 4). With moderately reduced propellant loading compared to the latest published information [37], due to more accurate assessment of fuel residuals in the tanks and feedlines, the structural index of the booster remains at $15.6 \%$ which is probably a realistic value for a large cryogenic reusable stage. The passenger stage mass is derived as listed in Table 5 . The total fluid and propellant mass includes all ascent, residual, and RCS propellants and the water needed for the active leading edge cooling. The stages’ MECO mass is approximately 151.2 Mg. Based on available subsystem sizing and empirical mass estimation relationships, the TSTO orbiter mass is derived as listed in Table 6. The total fluid and propellant mass includes all ascent, residual, and RCS propellants and the water needed for the active leading edge cooling. The stages' MECO mass including payload and upper stage is approximately $145.2 \mathrm{Mg}$.

Table 4: Mass data of SpaceLiner 7-3 booster stage

\begin{tabular}{|c|c|c|c|c|c|c|}
\hline $\begin{array}{c}\text { Structure } \\
{[\mathrm{Mg}]}\end{array}$ & $\begin{array}{c}\text { Propulsion } \\
{[\mathrm{Mg}]}\end{array}$ & $\begin{array}{c}\text { Subsystem } \\
{[\mathrm{Mg}]}\end{array}$ & TPS $[\mathrm{Mg}]$ & $\begin{array}{c}\text { Total dry } \\
{[\mathrm{Mg}]}\end{array}$ & $\begin{array}{c}\text { Total } \\
\text { propellant } \\
\text { loading }[\mathrm{Mg}]\end{array}$ & GLOW [Mg] \\
\hline 123.5 & 36.9 & 18.9 & 19.1 & 198.4 & 1272 & 1467 \\
\hline
\end{tabular}

Table 5: Mass data of SpaceLiner 7-3 passenger stage

\begin{tabular}{|c|c|c|c|c|c|c|}
\hline $\begin{array}{c}\text { Structure } \\
{[\mathrm{Mg}]}\end{array}$ & $\begin{array}{c}\text { Propulsion } \\
{[\mathrm{Mg}]}\end{array}$ & $\begin{array}{c}\text { Subsystems } \\
\text { including } \\
\text { cabin }[\mathrm{Mg}]\end{array}$ & $\begin{array}{c}\text { TPS [Mg] } \\
\text { (metallic upper } \\
\text { surface) }\end{array}$ & $\begin{array}{c}\text { Total dry } \\
{[\mathrm{Mg}]}\end{array}$ & $\begin{array}{c}\text { Total fluid \& } \\
\text { propellant } \\
\text { loading [Mg] }\end{array}$ & $\begin{array}{c}\text { GLOW incl. } \\
\text { passengers \& } \\
\text { payload[Mg] }\end{array}$ \\
\hline 55.3 & 9.7 & 43.5 & 22.3 & 129 & 232.1 & 366 \\
\hline
\end{tabular}

Table 6: Mass data of SpaceLiner 7 Orbiter stage (GTO mission)

\begin{tabular}{|c|c|c|c|c|c|c|}
\hline $\begin{array}{c}\text { Structure } \\
{[\mathrm{Mg}]}\end{array}$ & $\begin{array}{c}\text { Propulsion } \\
{[\mathrm{Mg}]}\end{array}$ & $\begin{array}{c}\text { Subsystems } \\
{[\mathrm{Mg}]}\end{array}$ & TPS [Mg] & $\begin{array}{c}\text { Total dry } \\
{[\mathrm{Mg}]}\end{array}$ & $\begin{array}{c}\text { Total fluid \& } \\
\text { propellant } \\
\text { loading [Mg] }\end{array}$ & $\begin{array}{c}\text { GLOW incl. } \\
\text { kick-stage \& } \\
\text { payload [Mg] }\end{array}$ \\
\hline 60.1 & 9.9 & 9.8 & 22.3 & 102 & 207 & 309.1 \\
\hline
\end{tabular}

The SpaceLiner 7-3's GLOW reaches about 1832 Mg (Table 7) for the reference mission Australia - Europe while the TSTO is at $1807 \mathrm{Mg}$ (Table 8); still considerably below that of the Space Shuttle STS of more than $2000 \mathrm{Mg}$ and therefore technically within reach.

Table 7: Mass data of SpaceLiner 7-3 passenger launch configuration

\begin{tabular}{|c|c|c|}
\hline $\begin{array}{c}\text { Total dry } \\
{[\mathrm{Mg}]}\end{array}$ & $\begin{array}{c}\text { Total } \\
\text { propellant } \\
\text { loading }[\mathrm{Mg}]\end{array}$ & $\begin{array}{c}\text { GLOW incl. } \\
\text { passengers \& } \\
\text { payload }[\mathrm{Mg}]\end{array}$ \\
\hline 327.4 & 1502 & 1832.2 \\
\hline
\end{tabular}


Table 8: Mass data of SpaceLiner 7-3 TSTO launch configuration

\begin{tabular}{|c|c|c|}
\hline $\begin{array}{c}\text { Total dry } \\
{[\mathrm{Mg}]}\end{array}$ & $\begin{array}{c}\text { Total } \\
\text { propellant } \\
\text { loading [Mg] }\end{array}$ & $\begin{array}{c}\text { GLOW incl. } \\
\text { kick-stage \& } \\
\text { payload [Mg] }\end{array}$ \\
\hline 300.6 & 1467 & 1807 \\
\hline
\end{tabular}

\section{SpaceLiner 7 Missions}

\section{A. Passenger Transport}

The ambitious west-bound Australia - Europe mission has been used as the reference case since the beginning of the SpaceLiner investigations. This flight distance should be served for 50 passengers on a daily basis in each direction. Several other, shorter intercontinental missions exist, which potentially generate a larger market demand. For this reason a SpaceLiner configuration derivative has been studied, which could transport up to 100 passengers [20, 34].

The launch and ascent noise as well as the sonic boom reaching ground are most critical for a viable SpaceLiner operation in the future. The selection of potential SpaceLiner launch and landing sites will likely be influenced by constraints due to generated noise [20]. Therefore, operational scenarios of the SpaceLiner are established taking into account realistic launch- and landing sites as well as groundtracks which are acceptable with respect to sonic boom constraints overflying populated areas and fast accessibility to major business centers.

Conventional existing airports located close to densely populated areas are not suitable for SpaceLiner operations. Three alternative launch and landing site concepts should fit for almost all potential locations [50]:

- On-shore close to sea or ocean

- Artificial island

- Off-shore launch site \& on-shore landing site

All three options are not entirely new and have already been realized in the past. Obviously, these versions have all their advantages and disadvantages. A specific choice depends on the particular location where a spaceport is planned to be built with climate and geographical location playing an important role [50]. Such pre-selection has been performed based on a first systematic assessment on intercontinental high-speed connection options [51] of the SpaceLiner.

Different trajectory options have been traded in the past mostly for the Australia - Europe reference mission for up to 50 passengers. These were following a standard launch vehicle vertical ascent with an initial azimuth in NorthEastern direction overflying the arctic sea before approaching Europe from the North-Eastern Atlantic. This trajectory had already been established as baseline for the SpaceLiner 4 using ASTOS optimizations [14]. The propulsive phase of approximately 8 minutes duration is directly followed by hypersonic gliding succeeded by landing approach after approximately an additional hour and 20 minutes of flight.

The Europe - Australia and return route is the baseline for other investigations. As a preliminary and currently nonbinding assumption, the flight connection is assumed for two on-shore launch landing sites located in Queensland, Eastern Australia and in the German North-Sea-coastal region. Both locations have the advantage of the complete launch ascent and supersonic gliding approach capable of being performed over the sea while still being relatively close to each continent's major business centers. These are two key-requirements for successful future SpaceLiner operation.

The reference mission from Australia to Europe of the current SpaceLiner7-3 configuration is fully feasible, meeting all requirements imposed by the vehicle: dynamic pressure, acceleration and heat flux. The covered range is approximately $16000 \mathrm{~km}$ and the simulated flight time no more than 71 minutes to TAEM cylinder before final landing approach. The MECO conditions reached at the end of the ascent flight is approximately $7.2 \mathrm{~km} / \mathrm{s}$ in an altitude of $73.1 \mathrm{~km}$ and the flight path angle $\gamma$ is close to $0^{\circ}$. The corresponding maximum Mach number is slightly beyond 25 and approximately $9000 \mathrm{~km}$ (more than $50 \%$ of the overall distance) are flown at Mach numbers larger than 20 (Figure 23). 

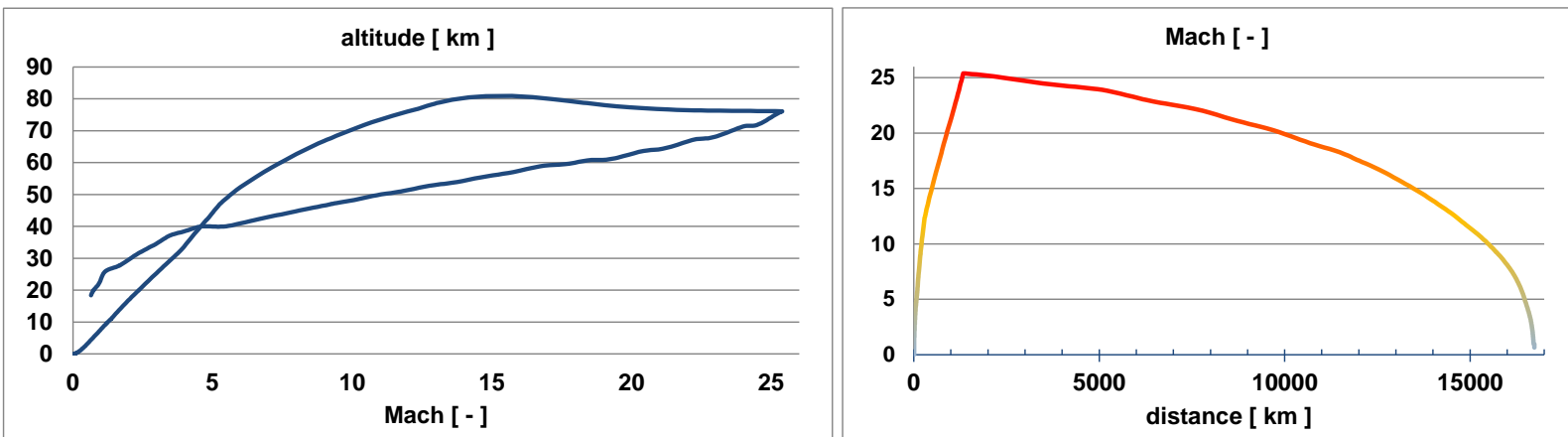

Figure 23: SpaceLiner 7-3 simulated ascent and descent trajectory data for nominal mission Australia to Europe

The descent ground track of the nominal reference mission and the potential return flight are shown in Figure 24 . Noise and sonic boom impact on inhabited areas is very low and actual proof of full public acceptability of the vehicle flying at very high altitude is under assessment.

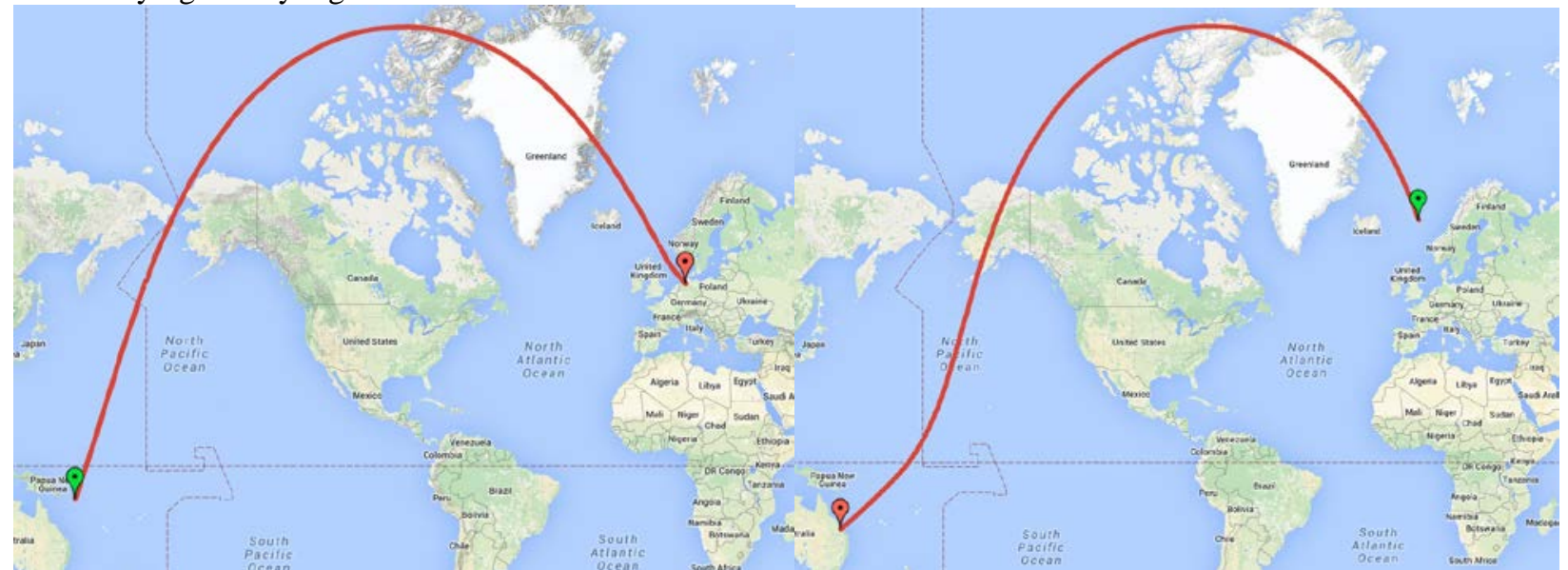

Figure 24: Simulated SpaceLiner 7-3 descent ground track nominal mission Australia to Europe (left) and Europe to Australia (right)

Three off-nominal cases have been simulated: Engine Isp degraded by $3 \mathrm{~s}$ under all conditions (equivalent to a c*reduction of $29.4 \mathrm{~m} / \mathrm{s}$ ). In a conservative approach the assumption is that all engines are affected. Further, nominal ascent propellant mass in the booster stage has been reduced by 20 tons while increasing residuals and reserves by the same amount. The third off-nominal case is the impact of one engine inoperative: the entire ascent phase is simulated with only 8 booster engines, instead of 9 . Flight times are slightly increased and realized ground tracks are somewhat altered. However, in all investigated cases the mission success has been demonstrated even under significantly degraded off-nominal conditions.

The flight route from Australia to North-East America, previously never investigated for the SpaceLiner, has now been studied and is found more difficult and challenging to be achieved under similar constraints. Although it is possible to reach the East Coast of the United States, either approaching from the north or the south, the assumed potential launch sites for return trajectories were not suitable to complete the mission. The proposal for a new launch site on the west coast of Florida seems to be most promising for the North East America - Australia mission. However, this option might cause problems during the ascent phase over a highly traffic loaded area (Gulf of Mexico).

In order to reduce the working time for the determination of active controls (angle-of-attack and bank angle) during descent, the additional use of preliminary re-entry guidance has been proposed, developed and tested on many different trajectories and circumstances. The algorithm implemented in Scilab ${ }^{\circledR}$ allows accurately assessing the value of bank angle capable to cover the range determined by the great circle arc approximation, keeping the angle of attack fixed. The use of a model based on the drag acceleration appears to be efficient for the determination of the bank angle and simulation results indicate the effectiveness of the guidance with a comparison between drag 
acceleration resulting from 3DOF trajectory simulation and the reference value estimated by the Scilab ${ }^{\circledR}$ script. Moreover, the introduction of an intermediate waypoint in the route allows respecting in a better way the requirement of not to overfly highly populated areas.

All the results of the application of this guidance on entry trajectories so far examined show the potential of the algorithm but also its limitations. Additional work in the future will refine the method and should allow for fast trade-offs on different feasible flight routes under multiple constraints.

\section{B. TSTO satellite launcher}

The SpaceLiner 7 passenger transport is an ideal technical basis for a two-stage fully reusable satellite launch vehicle. The passenger transport is reaching almost orbital speed at MECO during its reference mission (see previous section). The baseline design of the orbital launcher remains unchanged to the passenger version (Figure 3) with a fully reusable booster and passenger stage arranged in parallel and the external shapes will be very similar. This approach intends enabling dramatic savings on development cost and moreover by manufacturing the vehicles on the same production line, also significantly lower hardware cost than would result for a dedicated new lay-out. The satellite launch configuration as shown in Figure 25 is described in more detail in [37].

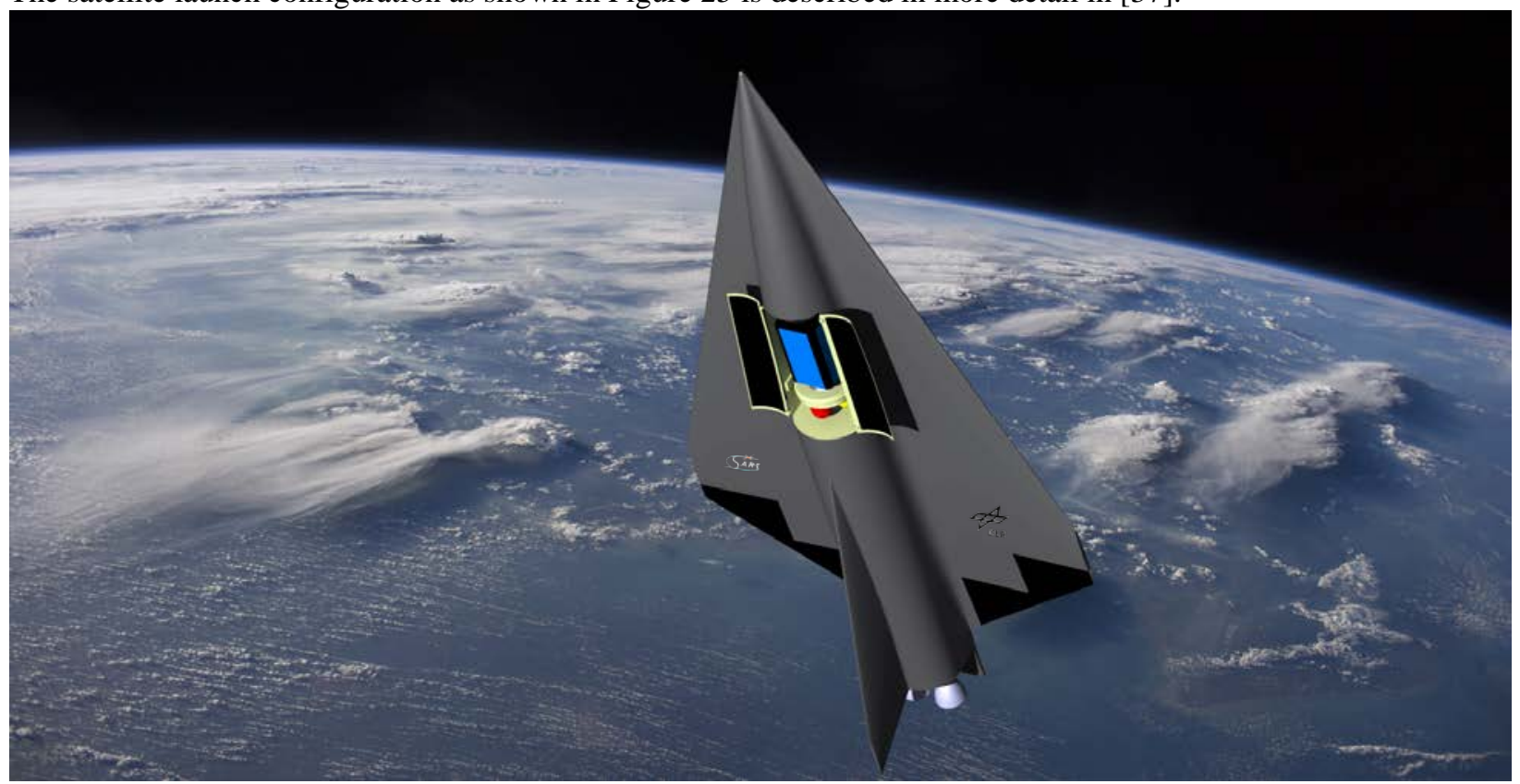

Figure 25: Artists impression of satellite payload release from SpaceLiner 7 Orbiter's open payload bay in LEO

Launch of the SpaceLiner 7 TSTO has been simulated from the Kourou space center into a low $30 \mathrm{~km} \times 250 \mathrm{~km}$ transfer orbit. Actually, this trajectory allows at least for the GTO mission that the orbiter stage becomes a oncearound-Earth-vehicle capable of reaching its own launch site after a single circle around the planet. As a consequence, the achievable payload mass increases and overall complexity is reduced; e.g. an active deorbiting is not needed. Trajectory optimizations show that the orbiter is able to deliver internally more than $26150 \mathrm{~kg}$ of separable payload to the very low and unstable orbit. Subsequently, an orbital transfer is necessary from LEO to GTO.

The recent SpaceLiner 7 TSTO investigations focus on conventional transfer- or upper stages using high-thrust chemical propulsion. A generic storable propellant upper stage has been selected for payload transfer from $30 \mathrm{~km} \times$ $250 \mathrm{~km}$ to the $250 \mathrm{~km} \times 35786 \mathrm{~km}$ GTO. The duration of the ballistic phase available for upper stage and payload release starting after Orbiter MECO up to stage ignition in a safe distance is approximately $1600 \mathrm{~s}$. The optimum upper stage propellant loading (combination not yet selected but $\mathrm{I}_{\mathrm{sp}}$ set to realistic $324 \mathrm{~s}$ ) is slightly above 16 tons which permits a separated satellite mass in GTO of $8250 \mathrm{~kg}$. 
Return of the two reusable stages to the launch site is to be assured for any feasible option. The SpaceLiner Orbiter reentry has been simulated with an entry interface speed of approximately $7.37 \mathrm{~km} / \mathrm{s}$. Reaching its once-around destination CSG in Kourou is without problem for the orbiter due to its very good hypersonic $\mathrm{L} / \mathrm{D}$ well above 2 . The vehicle crosses Central America at high altitude and turns to the South over the Caribbean Sea. Almost no sonic boom should be audible on ground. The maximum heatloads remain slightly lower than for the reference passenger concept because of a different AoA-profile and lower vehicle mass. The preliminary assumption of a common TPS with the passenger stage is confirmed.

\section{Ascent flight Control}

Trajectory simulations of the SpaceLiner under nominal and off-nominal conditions as described above have usually been based on an idealized point-mass model. The unpowered gliding reentry of the passenger stage has been also assessed on its flying qualities [43]. In order to investigate the attitude dynamics of the asymmetric launcher configuration (Figure 3), a 6 DOF trajectory simulation has been established. The main objective of this model is to evaluate the controllability of the vehicle in all nominal and off-nominal flight conditions. Current studies of the flight dynamics are focusing exclusively on the ascent phase [52], while further extensions on other flight phases are under investigation.

Based on the current vehicle geometry, a rigid-body model of the SpaceLiner has been developed for the 6DOF trajectory simulation. As typical for every rocket launch system and even intensified by the propellant crossfeed from the booster to the passenger stage (see references 26, 35!), the CoG is subject to a major movement during mated ascent flight. Right before stage separation when the booster propellant tanks are almost drained, the CoG had moved $21.7 \mathrm{~m}$ backward and $3.4 \mathrm{~m}$ towards the attached upper stage (Figure 26). These transient changes of the CoG, as well as of the vehicle's inertia tensor, are modeled by a preliminary three-dimensional allocation of subsystem and propellant masses inside the vehicle. Since this model describes the SpaceLiner as a rigid body, fuel sloshing and any dynamic deformations or aeroelastic effects are neglected.

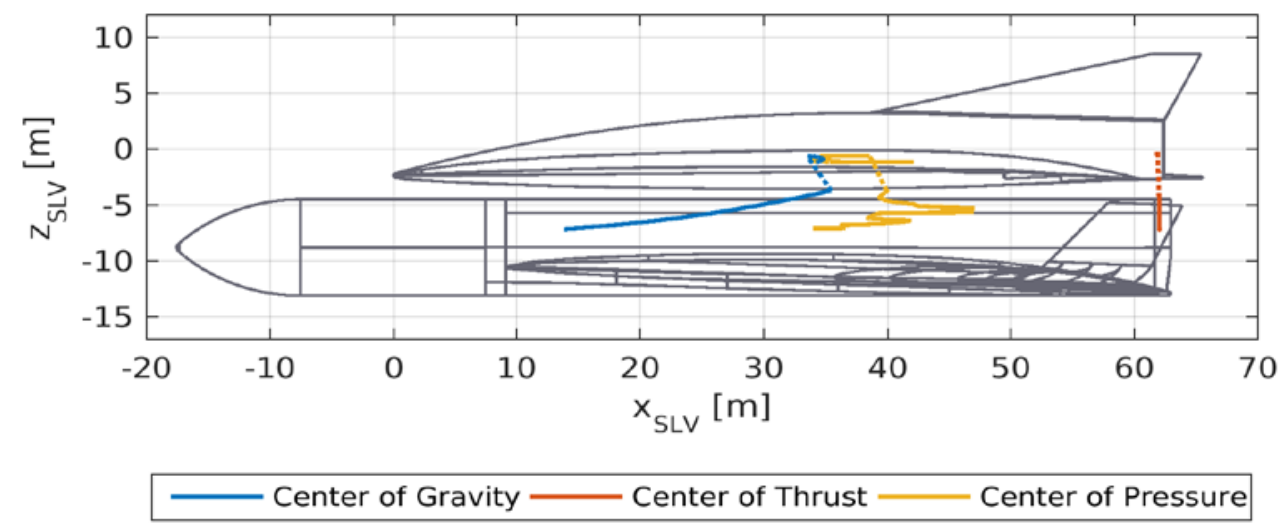

Figure 26: Transient movement of center of gravity, approximate center of pressure and center of thrust during ascent flight; instantaneous jump at stage separation indicated by dashed lines

The aerodynamic characteristics of the SpaceLiner also change significantly during ascent flight as the vehicle is passing through sub-, super- and hypersonic flow regimes with dynamic pressures between $0.1-30 \mathrm{kPa}$. For modeling the aerodynamic coefficients of the SpaceLiner in all flight conditions, the aerodynamic reference database has been utilized [36]. This dataset has additionally been extended by lateral and dynamic derivatives of the aerodynamic coefficients, preliminarily estimated by simple empirically derived engineering methods [53].

\section{Flight Control Model and Design of the Flight Controller}

During ascent flight the SpaceLiner trajectory is primarily controlled by the thrust vector control system (TVC). Its main task is to trim the variable position of the COG as well as the aerodynamic moments by means of gimballing the SpaceLiner Main Engines. In particular, for pitch control all engines are deflected simultaneously in vertical direction, while yaw control is provided by equivalent lateral deflections. Roll control is executed during mated ascent by inducing an additional horizontal deflection of the passenger stage engines only. After stage separation roll control is realized by differential vertical deflections of these two engines. 
For the 6DOF trajectory simulation of the SpaceLiner a preliminary flight control model has been developed which is controlling the TVC actuators. As shown in Figure 27 the control model is designed as a cascade control, adapting the classical design of flight controllers for airplanes [54]. Here, the inner feedback loop is controlling the vehicle's attitude, while the outer feedback loop is providing flight path control. Derived from the nominal ascent trajectory the target states of the vehicle are commanded to the control model.

In order to adapt the controller settings to the changing vehicle properties of the SpaceLiner model, all feedback gains are scheduled in dependence of the mission elapsed time. The feedback gains are designed for each operating point by a semi-automatic relay autotuning algorithm [55], which is utilizing empirical tuning rules [ZieglerNichols]. This approach allows a rapid control prototyping of the flight controller during the iterative design process of the SpaceLiner.

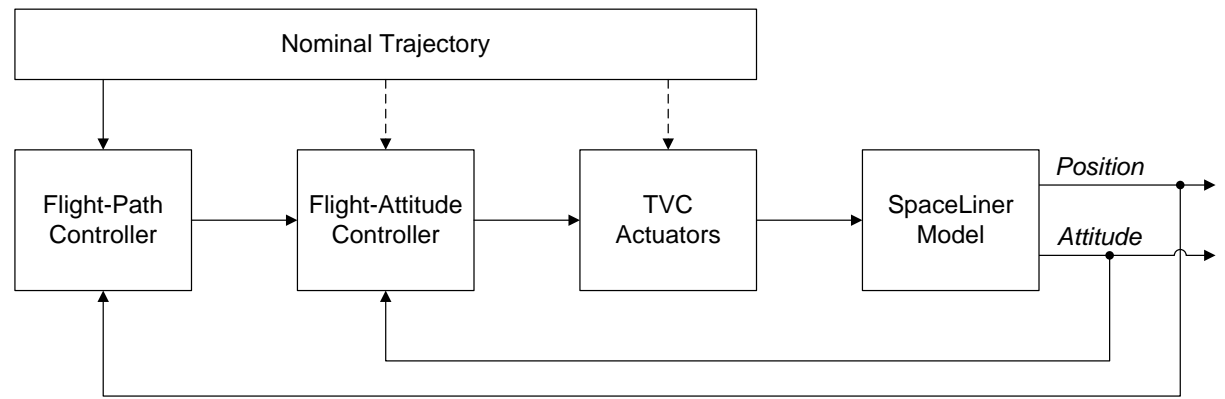

Figure 27: Top-Level structure of the implemented flight control model

\section{Dynamic Simulation of Ascent Flight Control}

Based on the developed SpaceLiner model a simulation study has been concluded investigating the flight dynamics of the SpaceLiner on the reference mission from Australia to Europe. Besides the determination of the undisturbed ascent trajectory, this study considers also simulation cases with atmospheric disturbances including geographic mean wind profiles [56] and stochastic gusts up to medium intensities [57].

In all regarded cases only minor deviations between the simulated 6DOF trajectories and the nominal trajectory, defined by a simplified 3DOF simulation, could be identified. The maximum lateral displacement of the SpaceLiner with respect to the nominal trajectory remained below $60 \mathrm{~m}$ in any flight condition, while the maximum vertical displacement was limited to $110 \mathrm{~m}$. These positioning accuracies can be considered as non-critical for the mission success as they are in a similar order of magnitude as the vehicle's dimensions. Furthermore, potential for safe launch tower clearance has been verified since all displacements in this early flight phase remain below $1.2 \mathrm{~m}$.

Generally, all 6DOF simulation cases are showing slightly higher $\Delta \mathrm{v}$ losses of 4 - $5 \mathrm{~m} / \mathrm{s}$ compared to the nominal 3DOF trajectory, which are induced by the SpaceLiner's attitude dynamics. In terms of the specific kinetic energy change of the vessel during ascent flight, this performance reduction is less than $0.1 \%$ and therefore can easily be covered by the current design margins of the SpaceLiner. No critical influence of the atmospheric disturbances on the vehicle's performance could be identified at all.

An important aspect for the dimensioning of the TVC actuators and the assessment of the feasibility of the control system are the maximum required TVC deflection angles. Figure 28 shows the necessary deflections of the SpaceLiner Main Engines for closely following the reference track as obtained from a dynamic ascent flight simulation assuming an undisturbed atmosphere. The trim settings required for achieving static equilibrium of moments at each trajectory point are indicated by dashed lines. Differences are minor with largest deviation at maximum dynamic pressure.

The influences of the CoG-movement and of the asymmetric engine throttling are clearly visible. As can be seen, the maximum vertical deflections are limited to $\pm 2.5^{\circ}$ while the lateral deflection angles remain below $\pm 0.6^{\circ}$. Crosswinds are significantly increasing the necessary deflections for roll control, raising the lateral deflection range up to $\pm 1.4^{\circ}$ in the disturbed simulation cases. However, these deflection angles are far below the gimbal limit of $\pm 8.5^{\circ}$ of typical rocket engines providing good control margins. 

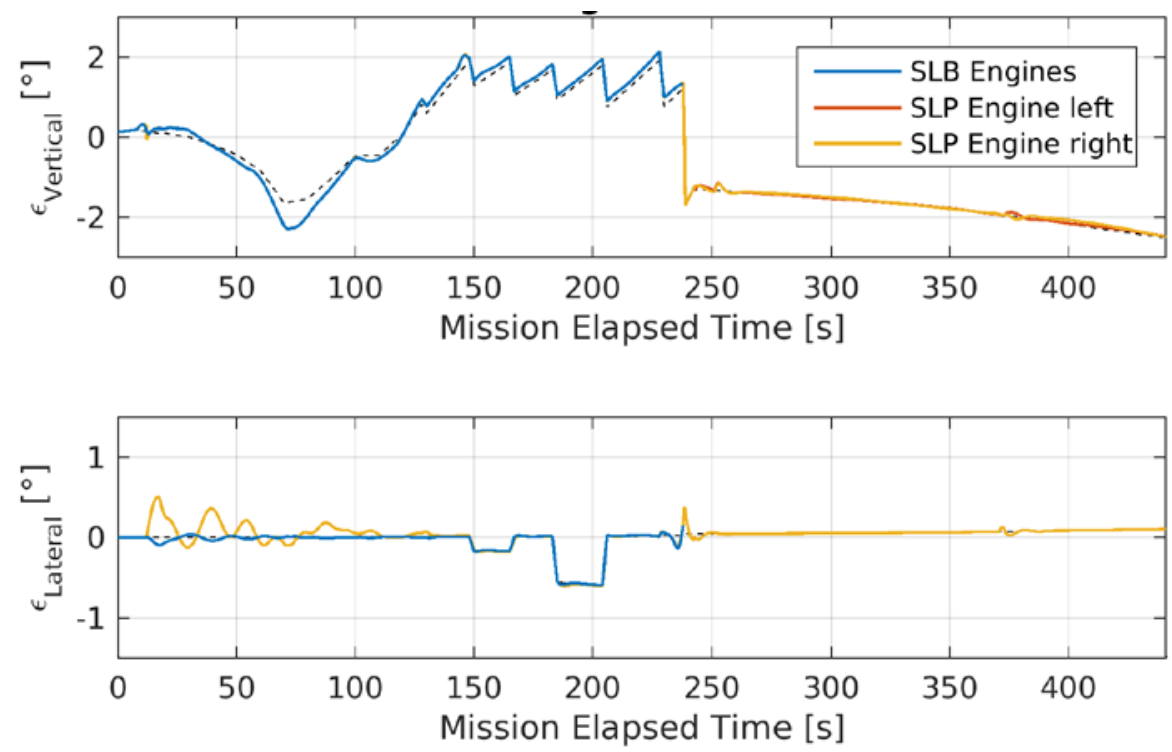

Figure 28: Vertical and lateral deflections of the TVC actuators during ascent flight in simulation case without atmospheric disturbances

Regarding the vehicle dynamics during ascent flight, no evidence has been found which would contradict the general controllability of the SpaceLiner. The trimmability of the aerodynamic moments by the TVC system has been proven for all nominal and several off-nominal flight conditions up to lateral aerodynamic pressures of q $\alpha \leq$ $2000 \mathrm{~Pa} \cdot \mathrm{rad}$ and $\mathrm{q} \beta \leq 1500 \mathrm{~Pa} \cdot \mathrm{rad}$. No stability issues could be identified on the simulated trajectories, even though aerodynamic stability cannot be ensured in altitudes above $50 \mathrm{~km}$ due to the lack of sufficient aerodynamic pressure. All flight commands have been tracked well by the developed flight control model avoiding corrective maneuvers with excessive aerodynamic angles or loads even in case of moderate atmospheric disturbances.

Additional simulation cases are currently under investigation, analyzing more critical mission scenarios including off-nominal flight conditions. These consider stronger atmospheric disturbances and anomalies in vehicle operations like unplanned thrust loss due to engine-failure. The objective of these analyses is to determine the safe operational flight envelope of the SpaceLiner.

\section{Conclusion}

The DLR proposed reusable winged rocket SpaceLiner for very high-speed intercontinental passenger transport has successfully completed its Mission Requirements Review (MRR) in summer 2016 and is progressing in its conceptual design phase. Research on the vehicle has been performed with support from the EU projects FAST20XX, CHATT, HIKARI and HYPMOCES with several European partners. Assuming advanced but not exotic technologies, a vertically launched rocket powered two stage space vehicle is able to transport about 50 passengers over distances of up to $17000 \mathrm{~km}$ in about 1.5 hours.

The passenger rescue capsule, designed to be used in cases of extreme emergencies, has been further elaborated and major subsystems have been defined. Sophisticated CFD-calculations have been performed and allow a better understanding of the challenging aerothermal environment. The principal feasibility and flyability of an innovative morphing structure concept on the capsule has been demonstrated by numerical simulations. In this case the maximum hypersonic L/D-ratio of the capsule is improved by up to $20 \%$ compared to the standard configuration. The additional mass and system complexity is to be justified by significantly improved passenger safety.

A newly designed, fully reusable TSTO satellite transport version of the SpaceLiner with internal cargo bay but overall very similar lay-out to the passenger transport has been defined. Iterative design with simulation of all stage's trajectories demonstrate that larger than 8 tons separated satellite mass can be lifted into GTO when using an additional expendable kick-stage. Simulations proof that the SpaceLiner TSTO version stays within the load constraints of the PAX-version which confirms that the baseline design can be reused without major development 
effort. Based on the production cost assessment of the passenger transport, attractive specific launch cost of less than $2000 € / \mathrm{kg}$ in GTO and less than $1000 € / \mathrm{kg}$ in LEO are achievable.

Potential worldwide flight routes under realistic operational and environmental constraints are under investigation considering advanced flight control and guidance methods. Simulated 6DOF ascent trajectories demonstrate the robust behavior of the Thrust Vector Control system showing significant margins even in case of wind and gusts interacting with the winged configuration.

\section{Acknowledgements}

Part of this work was performed within the 'Future High-Altitude High-Speed Transport 20XX' project investigating high-speed transport. FAST20XX, coordinated by ESA-ESTEC, is supported by the EU within the 7th Framework Programme Theme7 Transport, Contract no.: ACP8-GA-2009-233816.

Part of this work was performed within the 'Cryogenic Hypersonic Advanced Tank Technologies' project investigating tank technologies for high-speed transport. CHATT, coordinated by DLR-SART, is supported by the EU within the 7th Framework Programme Theme 7 Transport, Contract no.: ACP1-GA-2011-285117.

Further, part of the research leading to these results has received funding from the European Union's Seventh Framework Programme FP7/2007-2013 under grant agreement $n^{\circ}$ AAT-2012-RTD-341531 entitled "Hypersonic Morphing for a Cabin Escape System (HYPMOCES)”.

The authors gratefully acknowledge the contributions of Ms. Olga Trivailo, Ms. Sarah Lipp, Ms. Carola Bauer, Ms. Mona Carlsen, Ms. Nicole Garbers, Ms. Carina Ludwig, Ms. Elena Casali, Mr. Gero Förster, Mr. Ryoma Yamashiro, Mr. G. Gambacciani, Mr. Izan Peris Marti, Mr. Magni Johannsson, Mr. David Gerson, Mr. Jochen Bütünley, Mr. Aron Lentsch, Mr. G. Zuppardi, Mr. Luigi Morsa, Mr. Ola Rasmusson, Mr. Bernd Madauss, Mr. Jürgen Herholz, Mr. Raffaele Votta, and Mr. Rafael Molina to the preliminary design of the SpaceLiner.

\section{References}

1. Sippel, M., Klevanski, J., Steelant, J.: Comparative Study on Options for High-Speed Intercontinental Passenger Transports: Air-Breathing- vs. Rocket-Propelled, IAC-05-D2.4.09, October 2005

2. Sippel, M., Klevanski, J., van Foreest, A., Gülhan, A., Esser, B., Kuhn, M.: The SpaceLiner Concept and its Aerothermodynamic Challenges, $1^{\text {st }}$ ARA-Days, Arcachon July 2006

3. Sippel, M.; Klevanski, J.: Preliminary Definition of the Supersonic and Hypersonic Airliner Configurations in LAPCAT, AIAA 2006-7984, $14^{\text {th }}$ Spaceplanes Conference, November 2006

4. van Foreest, A., Sippel, M., Klevanski, J., Gülhan, A., Esser, B.: Technical Background and Challenges of the SpaceLiner Concept, $7^{\text {th }}$ International Symposium on Launcher Technologies, Barcelona, Spain, April 2-5, 2007

5. Sippel, M.: Introducing the SpaceLiner Vision, $7^{\text {th }}$ International Symposium on Launcher Technologies, Barcelona, Spain, April 2-5, 2007

6. van Foreest, A.; Sippel, M.: The Logistical Challenges of the SpaceLiner Concept, IAA $1^{\text {st }}$ Symposium on Private Human Access to Space, Arcachon May 28-30 2008

7. Sippel, M.: Promising roadmap alternatives for the SpaceLiner, Acta Astronautica, Vol. 66, Iss. 11-12, (2010)

8. Sippel, M.: SpaceLiner - a Visionary Concept of an Ultra Fast Passenger Transport under Investigation in FAST20XX, AIAA 2009-7439, $16^{\text {th }}$ AIAA/DLR/DGLR International Space Planes and Hypersonic Systems and Technologies Conference, Bremen 2009

9. Trivailo, O. et.al.: SpaceLiner Mission Requirements Document, SL-MR-SART-00001-1/2, Issue 1, Revision 2, SART TN-005/2016, 11.07.2016

10. Sippel, M., van Foreest, A.: SpaceLiner Rocket-Powered High-Speed Passenger Transportation Concept Evolving in FAST20XX, IAC-10-D2.4.06, September 2010

11. Van Foreest, A. , Sippel, M.; Gülhan, A.; Esser, B.; Ambrosius, B.A.C.; Sudmeijer, K.: Transpiration Cooling Using Liquid Water, Journal of Thermophysics and Heat Transfer, Vol. 23, No. 4, October-December 2009 
12. Kopp, A.; van Foreest, A., Sippel, M.; Dalenbring, M.; Jarlas, R.: Investigation of Structure for the Hypersonic Transport System SpaceLiner, AIAA 2011-2373, 17 ${ }^{\text {th }}$ AIAA International Space Planes and Hypersonic Systems and Technologies Conference, April 2011

13. Neeb, D., Schwanekamp, T., Gülhan, A.: Preliminary Aerodynamic Shape Optimization of the SpaceLiner by Means of Engineering Methods, AIAA 2011-2299, $17^{\text {th }}$ AIAA International Space Planes and Hypersonic Systems and Technologies Conference, April 2011

14. Sippel, M. van Foreest, A.; Bauer, C.; Cremaschi, F.: System Investigations of the SpaceLiner Concept in

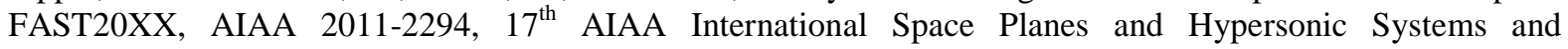
Technologies Conference, April 2011

15. Sippel, M.; van Foreest, A.; Dietlein, I.; Schwanekamp, T.; Kopp, A.: System Analyses Driving Improved Aerothermodynamic Lay-out of the SpaceLiner Configuration, ESA-SP692, May 2011

16. Reimer, Th.; Kuhn, M.; Gülhan, A.; Esser, B.; Sippel, M.; van Foreest, A.: Transpiration Cooling Tests of Porous CMC in Hypersonic Flow, AIAA2011-2251, $17^{\text {th }}$ International Space Planes and Hypersonic Systems and Technologies Conference, 2011

17. Sippel, M.; Kopp, A.; Sinko, K.: Advanced Hypersonic Cryo-Tanks Research in CHATT, AIAA2012-5945, $18^{\text {th }}$ AIAA International Space Planes and Hypersonic Systems and Technologies Conference, Tours, September 2012

18. Sippel, M.; Kopp, A.; Mattsson, D.; Freund, J.; Tapeinos, I.; Koussios, S.: Final Results of Advanced CryoTanks Research Project CHATT, $6{ }^{\mathrm{TH}}$ EUROPEAN CONFERENCE FOR AERONAUTICS AND SPACE SCIENCES (EUCASS) 2015, Krakow, July 2015

19. Blanvillain, E.: HIKARI: Paving the way towards High Speed Air Transport, AIAA 2015-3676, 20 ${ }^{\text {th }}$ AIAA International Space Planes and Hypersonic Systems and Technologies Conference, Glasgow, July 2015

20. Sippel, M.; Schwanekamp, T.; Bauer, C.; Garbers, N.; van Foreest, A.; Tengzelius, U.; Lentsch, A.: Technical Maturation of the SpaceLiner Concept, AIAA2012-5850, $18^{\text {th }}$ AIAA International Space Planes and Hypersonic Systems and Technologies Conference, Tours, September 2012

21. Garbers, N.: Overall Preliminary Design of the Thermal Protection System for a Long Range Hypersonic Rocket-Powered Passenger Vehicle (SpaceLiner), ESA TPS-HS Workshop 2013

22. Trivailo, O.; Sippel, M.; Lentsch, A.; Sekercioglu, A.: Cost Modeling Considerations \& Challenges of the SpaceLiner - An Advanced Hypersonic, Suborbital Spaceplane, AIAA Space2013 conference, San Diego, September 2013

23. Sippel, M.; Schwanekamp, T.; Trivailo, O.; Lentsch, A.: Progress of SpaceLiner Rocket-Powered High-Speed Concept, IAC-13-D2.4.05, IAC2013, Beijing, September 2013

24. Schwanekamp, T.; Morsa, L.; Zuppardi, G.; Molina, R.: SpaceLiner 7-2 Aerodynamic Reference Database, SART TN-026/2012, 2013

25. Sippel, M.; Schwanekamp, T.; Ortelt, M.: Staged Combustion Cycle Rocket Engine Subsystem Definition for Future Advanced Passenger Transport, Space Propulsion 2014, Cologne, Germany, May 2014

26. Schwanekamp, T.; Ludwig, C.; Sippel, M.: Cryogenic Propellant Tank and Feedline Design Studies in the Framework of the CHATT Project, $19^{\text {th }}$ AIAA International Space Planes and Hypersonic Systems and Technologies Conference, AIAA Aviation and Aeronautics Forum and Exposition, June 2014

27. Schwanekamp, T.; Bauer, C.; Kopp, A.: The Development of the SpaceLiner Concept and its Latest Progress, $4{ }^{\mathrm{TH}}$ CSA-IAA CONFERENCE ON ADVANCED SPACE TECHNOLOGY, Shanghai, September 2011

28. Bauer, C.; Garbers, N., Johannsson, M.; Lentsch, A.: INVESTIGATIONS OF THE SPACELINER PASSENGER CAPSULE AND VARIOUS ABORT SCENARIOS, DLRK 2012, September 2012

29. Kopp, A.; Garbers, N.; Jarlas, R.: Parametric Structural Analysis for the SpaceLiner, AIAA2012-5944, 18 ${ }^{\text {th }}$ AIAA International Space Planes and Hypersonic Systems and Technologies Conference, Tours, September 2012

30. Kopp, A., Garbers, N.: Structural and TPS Trade-Off Studies for the Hypersonic Transport System SpaceLiner, $13^{\text {th }}$ European Conference on Spacecraft Structures, Materials, and Environmental Testing, Braunschweig, Germany, April 2014

31. Jackson, J. R., Vickers, J., Fikes, J.: Composite Cryotank Technologies and Development 2.4 and 5.5M out of Autoclave Tank Test Results, Composites and Advanced Materials Expo (CAMX), Dallas, USA, October 2015 
32. Johnson, T. F.; Gates, T. S., High temperature polyimide materials in extreme temperature environments, AIAA-2001-1214, 42 ${ }^{\text {nd }}$ AIAA/ASME/ASCE/AHS/ASC Structures, Structural Dynamics, and Materials Conference and Exhibit, Seattle, Washington, April 2001

33. N. N.: APC-2 PEEK Thermoplastic Polymer, Cytec technical data sheet

34. Schwanekamp, T.; Bütünley, J.; Sippel, M.: Preliminary Multidisciplinary Design Studies on an Upgraded 100 Passenger SpaceLiner Derivative, AIAA 2012-5808, $18^{\text {th }}$ AIAA International Space Planes and Hypersonic Systems and Technologies Conference, Tours, September 2012

35. Sippel, M.; Schwanekamp, T; Trivailo, O; Kopp, A; Bauer, C; Garbers, N.: SpaceLiner Technical Progress and Mission Definition, AIAA 2015-3582, $20^{\text {th }}$ AIAA International Space Planes and Hypersonic Systems and Technologies Conference, Glasgow, July 2015

36. Sippel, M.; Schwanekamp, T.: The SpaceLiner Hypersonic System - Aerothermodynamic Requirements and Design Process, $8^{\text {th }}$ European Symposium on Aerothermodynamics for Space Vehicles, Lisbon, March 2015

37. Sippel, M., Trivailo, O., Bussler, L., Lipp, S., Kaltenhäuser, S.; Molina, R.: Evolution of the SpaceLiner towards a Reusable TSTO-Launcher, IAC-16-D2.4.03, September 2016

38. Bonetti, D. et al: Hypersonic Morphing for a Cabin Escape System: Results of First Design Loop, $8^{\text {th }}$ European Symposium on Aerothermodynamics for Space Vehicles, Lisbon 2015

39. Laroche, E.: Aerothermodynamics analysis of the Spaceliner Cabin Escape System modified via a morphing system, $8^{\text {th }}$ European Symposium on Aerothermodynamics for Space Vehicles, Lisbon 2015

40. Bauer, C.; Kopp, A.; Schwanekamp, T.; Clark, V.; Garbers, N.: Passenger Capsule for the SpaceLiner, DLRKpaper, Augsburg 2014

41. Schwanekamp, T. et al.: CONCURRENT ENGINEERING APPROACH FOR THE PRELIMINARY STUDY OF HYPERSONIC MORPHING FOR A CABIN ESCAPE SYSTEM, IAC-14.D1.3.10, 65 ${ }^{\text {th }}$ International Astronautical Congress, Toronto, 2014

42. Haya, R.; Costa, H.; Bonetti, D.; Schwanekamp, T.; Gambacciani, G.; Sourgen, F.; Laroche, E.: Hypersonic Morphing for a Cabin Escape System, IAC-14.D6.2-D2.9.2, 65 ${ }^{\text {th }}$ International Astronautical Congress (IAC), Sep 29-Oct 3, 2014, Toronto, Canada

43. Haya Ramos, R. et al: Aerodynamics and Flying Qualities Requirements for a Long-range Transportation System, $8^{\text {th }}$ European Symposium on Aerothermodynamics for Space Vehicles, Lisbon 2015

44. Bonetti, D.; Parigini, C.; De Zaiacomo, G.; Pontijas Fuentes, I.; Blanco Arnao, G.; Riley, D.; Sánchez Nogales, M.: PETBOX: FLIGHT QUALIFIED TOOLS FOR ATMOSPHERIC FLIGHT. 6 ${ }^{\text {th }}$ ICATT, 2016

45. Rosa, P.; Fabrizi, A.; Kerr, M.; Bonetti D.: Analytical and simulation-based V\&V techniques applied to hypersonic vehicles, EuroGNC 2015

46. Schwanekamp, T.; Mayer, F.; Reimer, T.; Petkov, I.; Tröltzsch, A.; Siggel, M.: System Studies on Active Thermal Protection of a Hypersonic Suborbital Passenger Transport Vehicle, AIAA Aviation Conference, AIAA 2014-2372, Atlanta, June 2014

47. Schwanekamp,T., Garbers, N.; Sippel, M.: Conceptual Design of the SpaceLiner Thermal Protection System, $8^{\text {th }}$ European Symposium on Aerothermodynamics for Space Vehicles, Lisbon 2015

48. Zuppardi, G.; Morsa, L.; Sippel, M.; Schwanekamp, T.: Aero-Thermo-Dynamic Analysis of the SpaceLiner-7.1 Vehicle in High Altitude Flight, Proceedings of the $29^{\text {th }}$ International Symposium on Rarefied Gas Dynamics, 2014, AIP Conf. Proc. 1628, 1268-1276 (2014); doi: 10.1063/1.4902737

49. Trivailo, O.: Innovative Cost Engineering Analyses and Methods Applied to SpaceLiner - an Advanced, Hypersonic, Suborbital Spaceplane Case-Study, PhD Thesis 2015

50. Lipp, S.; Bauer, C.; Trivailo, O.: Spaceport Concepts and Locations for the SpaceLiner, SART TN-022/2014, October 2014

51. Casali, E.; Bussler, L.; Sippel, M.: Investigation of feasible flight trajectories and re-entry atmospheric guidance for SpaceLiner 7, SART-TN014/2015, 2016

52. Krummen, S.: Investigation of flight dynamics and effects of rotational degrees of freedom on the flight performance of asymmetric space transportation systems based on the SpaceLiner 7 concept, SART TN010/2016, December 2016

53. Rosema, C.; Doyle, J.; Auman, L.; Underwood, M.; William, B.: Missle Datcom: User’s Manual - 2011 Revision, Air Force Research Laboratory, AFRL-RB-WP-TR-2011-3071, 2011 
54. Brockhaus, R.; Alles, W.; Luckner, R.: Flugregelung, 3rd ed., Springer, 2011

55. Aström, K. J., Hägglund, T.: Automatic Tuning of Simple Regulators with Specification on Phase and Amplitude Margins, Automatica, Vol. 20, No. 5, 1984, pp. 645-651

56. Hedin, A.E.; Fleming, E.L.; Manson, A.H.; Scmidlin, F.J.; Avery, S.K.; Clark, R.R.; Franke, S.J.; Fraser, G.J.; Tsunda, T.; Vial, F.; Vincent, R.A.: Empirical Wind Model for the Upper, Middle, and Lower Atmosphere, Journal of Atmospheric and Terrestrial Physics, Vol. 58, No. 13, pp. 1421-1447, 1996

57. U.S. Department of Defense: Flying Qualities of Piloted Aircraft, MIL-HDBK-1797, December 1997

Further updated information concerning the SART space transportation concepts is available at:

http://www.dlr.de/SART 